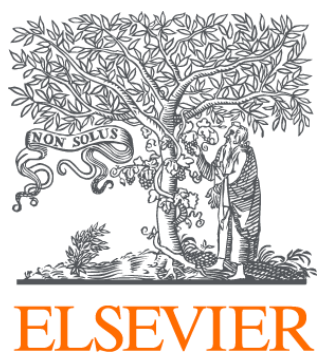

Since January 2020 Elsevier has created a COVID-19 resource centre with free information in English and Mandarin on the novel coronavirus COVID-

19. The COVID-19 resource centre is hosted on Elsevier Connect, the company's public news and information website.

Elsevier hereby grants permission to make all its COVID-19-related research that is available on the COVID-19 resource centre - including this research content - immediately available in PubMed Central and other publicly funded repositories, such as the WHO COVID database with rights for unrestricted research re-use and analyses in any form or by any means with acknowledgement of the original source. These permissions are granted for free by Elsevier for as long as the COVID-19 resource centre remains active. 


\section{Neurological associations of COVID-19}

Mark A Ellul, Laura Benjamin, Bhagteshwar Singh, Suzannah Lant, Benedict Daniel Michael, Ava Easton, Rachel Kneen, Sylviane Defres, Jim Sejvar, Tom Solomon

\section{Summary}

Background The COVID-19 pandemic, caused by severe acute respiratory syndrome coronavirus 2 (SARS-CoV-2), is of a scale not seen since the 1918 influenza pandemic. Although the predominant clinical presentation is with respiratory disease, neurological manifestations are being recognised increasingly. On the basis of knowledge of other coronaviruses, especially those that caused the severe acute respiratory syndrome and Middle East respiratory syndrome epidemics, cases of CNS and peripheral nervous system disease caused by SARS-CoV-2 might be expected to be rare.

Recent developments A growing number of case reports and series describe a wide array of neurological manifestations in 901 patients, but many have insufficient detail, reflecting the challenge of studying such patients. Encephalopathy has been reported for 93 patients in total, including 16 (7\%) of 214 hospitalised patients with COVID-19 in Wuhan, China, and 40 (69\%) of 58 patients in intensive care with COVID-19 in France. Encephalitis has been described in eight patients to date, and Guillain-Barré syndrome in 19 patients. SARS-CoV-2 has been detected in the CSF of some patients. Anosmia and ageusia are common, and can occur in the absence of other clinical features. Unexpectedly, acute cerebrovascular disease is also emerging as an important complication, with cohort studies reporting stroke in 2-6\% of patients hospitalised with COVID-19. So far, 96 patients with stroke have been described who frequently had vascular events in the context of a pro-inflammatory hypercoagulable state with elevated C-reactive protein, D-dimer, and ferritin.

Where next? Careful clinical, diagnostic, and epidemiological studies are needed to help define the manifestations and burden of neurological disease caused by SARS-CoV-2. Precise case definitions must be used to distinguish nonspecific complications of severe disease (eg, hypoxic encephalopathy and critical care neuropathy) from those caused directly or indirectly by the virus, including infectious, para-infectious, and post-infectious encephalitis, hypercoagulable states leading to stroke, and acute neuropathies such as Guillain-Barré syndrome. Recognition of neurological disease associated with SARS-CoV-2 in patients whose respiratory infection is mild or asymptomatic might prove challenging, especially if the primary COVID-19 illness occurred weeks earlier. The proportion of infections leading to neurological disease will probably remain small. However, these patients might be left with severe neurological sequelae. With so many people infected, the overall number of neurological patients, and their associated health burden and social and economic costs might be large. Health-care planners and policy makers must prepare for this eventuality, while the many ongoing studies investigating neurological associations increase our knowledge base.

\section{Introduction}

As of May 19, 2020, the COVID-19 pandemic, caused by the novel coronavirus severe acute respiratory syndrome coronavirus 2 (SARS-CoV-2), has resulted in more than 4.8 million confirmed cases worldwide and more than 300000 deaths. ${ }^{1}$ It is the largest and most severe pandemic since the 1918 influenza pandemic. ${ }^{2}$ Although the most common and important presentation is with respiratory disease, reports of neurological features are increasing. These features appear to be a combination of nonspecific complications of systemic disease, the effects of direct viral infection, or inflammation of the nervous system and vasculature, which can be para-infectious or post-infectious. In this Rapid Review, we consider which neurological manifestations might be expected for COVID-19, given what is known about related coronaviruses and respiratory viruses more broadly. We summarise the evidence to date for COVID-19, examine putative disease mechanisms, and finally suggest a framework for investigating patients with suspected COVID-19-associated neurological disease to support clinico-epidemiological, disease mechanism, and treatment studies.

\section{Evidence from other viruses}

Before identification of SARS-CoV-2, six coronaviruses were known to infect humans. Four of these coronaviruses cause seasonal, predominantly mild respiratory illness, and have a high incidence globally, accounting for $15-30 \%$ of upper respiratory tract infections. ${ }^{3}$ The other two coronaviruses have led to major epidemics with deaths principally from respiratory disease; severe acute respiratory syndrome (SARS) was caused by SARS-CoV in 2002-03, and Middle East respiratory syndrome (MERS) by MERS-CoV in 2012. ${ }^{4,5}$ Both the more innocuous coronaviruses and these epidemic strains have been associated with occasional disease of the CNS and peripheral nervous system (PNS).

Both CNS and PNS disease were reported following SARS (appendix pp 2-3). SARS-CoV was detected in CSF by RT-PCR in two of three cases of encephalopathy with seizures, ${ }^{6,7}$ and was cultured from brain tissue at autopsy
Lancet Neurol 2020; 19: 767-83 Published Online July 2, 2020 https://doi.org/10.1016/ S1474-4422(20)30221-0 See Comment page 713 National Institute for Health Research Health Protection Research Unit in Emerging and Zoonotic Infections, Institute of Infection, Veterinary and Ecological Sciences, University of Liverpool, Liverpool, UK (M A Ellul MRCP, B Singh MRCP, S Lant MBChB, B D Michael PhD $A$ Easton PhD, S Defres MRCP, Prof T Solomon FRCP); The Walton Centre National Health Service (NHS) Foundation Trust, Liverpool, UK (M A Ellul, B D Michael, Prof T Solomon); Queen Square Institute of Neurology, University College London, London, UK (L Benjamin PhD); Tropical and Infectious Diseases Unit, Royal Liverpool and Broadgreen University Hospitals NHS Trust, Liverpool, UK (B Singh, S Defres, Prof T Solomon); Christian Medical College, Vellore, India (B Singh); Encephalitis Society, Malton, UK (A Easton); Alder Hey Children's NHS Foundation Trust, Liverpool, UK

(R Kneen FRCPCH); and Division of High-Consequence Pathogens and Pathology, National Center for Emerging and Zoonotic Infectious Diseases, Centers for Disease Control and Prevention, Atlanta, GA, USA (J Sejvar MD) Correspondence to: Prof Tom Solomon, National Institute for Health Research Health Protection Research Unit in Emerging and Zoonotic Infections, Institute of Infection, Veterinary and Ecological Sciences, University of Liverpool, Liverpool L69 7BE, UK tsolomon@liverpool.ac.uk 


\begin{tabular}{|c|c|c|c|c|c|c|c|c|c|c|}
\hline & \multirow[t]{2}{*}{$\begin{array}{l}\text { SARS case } \\
\text { count } \\
(n=8096)\end{array}$} & \multirow[t]{2}{*}{$\begin{array}{l}\text { MERS case } \\
\text { count } \\
(n=2228)\end{array}$} & \multicolumn{2}{|c|}{$\begin{array}{l}\text { COVID-19 worldwide } \\
\text { minimum case count } \\
(n=4872308)\end{array}$} & \multicolumn{2}{|c|}{$\begin{array}{l}\text { COVID-19 minimum case } \\
\text { count in China }(n=84500)\end{array}$} & \multicolumn{2}{|c|}{$\begin{array}{l}\text { COVID-19 minimum case } \\
\text { count in USA }(n=1464232)\end{array}$} & \multicolumn{2}{|c|}{$\begin{array}{l}\text { COVID-19 minimum case } \\
\text { count in UK }(n=246410)\end{array}$} \\
\hline & & & $\begin{array}{l}\text { Extrapolated } \\
\text { from SARS } \\
(95 \% \mathrm{Cl})\end{array}$ & $\begin{array}{l}\text { Extrapolated } \\
\text { from MERS } \\
(95 \% \mathrm{Cl})\end{array}$ & $\begin{array}{l}\text { Extrapolated } \\
\text { from SARS } \\
(95 \% \mathrm{Cl})\end{array}$ & $\begin{array}{l}\text { Extrapolated } \\
\text { from MERS } \\
(95 \% \mathrm{Cl})\end{array}$ & $\begin{array}{l}\text { Extrapolated } \\
\text { from SARS } \\
(95 \% \mathrm{Cl})\end{array}$ & $\begin{array}{l}\text { Extrapolated } \\
\text { from MERS } \\
(95 \% \mathrm{Cl})\end{array}$ & $\begin{array}{l}\text { Extrapolated } \\
\text { from SARS } \\
(95 \% \mathrm{Cl})\end{array}$ & $\begin{array}{l}\text { Extrapolated } \\
\text { from MERS } \\
(95 \% \mathrm{Cl})\end{array}$ \\
\hline $\begin{array}{l}\text { Patients with CNS } \\
\text { disease (proportion } \\
\text { of total coronavirus } \\
\text { cases }[95 \% \mathrm{Cl}] \text { ) }\end{array}$ & $\begin{array}{l}3(0 \cdot 04 \% \\
[0 \cdot 01-0 \cdot 10])\end{array}$ & $\begin{array}{l}5(0.20 \% \\
[0.06-0.50])\end{array}$ & $\begin{array}{l}1805 \\
(370-5277)\end{array}$ & $\begin{array}{c}9671 \\
(3143-22539)\end{array}$ & $\begin{array}{l}31 \\
(6-92)\end{array}$ & $\begin{array}{l}168 \\
(55-391)\end{array}$ & $\begin{array}{l}543 \\
(111-1586)\end{array}$ & $\begin{array}{l}2906 \\
(944-6774)\end{array}$ & $\begin{array}{l}91 \\
(19-267)\end{array}$ & $\begin{array}{l}489 \\
(159-1140)\end{array}$ \\
\hline $\begin{array}{l}\text { Patients with PNS } \\
\text { disease (proportion } \\
\text { of total coronavirus } \\
\text { cases }[95 \% \mathrm{Cl}] \text { ) }\end{array}$ & $\begin{array}{l}4(0.05 \% \\
[0 \cdot 01-0 \cdot 13])\end{array}$ & $\begin{array}{l}4(0.16 \% \\
[0 \cdot 04-0 \cdot 41])\end{array}$ & $\begin{array}{l}2407 \\
(658-6163)\end{array}$ & $\begin{array}{l}7737 \\
(2110-19786)\end{array}$ & $\begin{array}{l}42 \\
(11-107)\end{array}$ & $\begin{array}{l}134 \\
(37-343)\end{array}$ & $\begin{array}{l}723 \\
(198-1852)\end{array}$ & $\begin{array}{l}2325 \\
(634-5946)\end{array}$ & $\begin{array}{l}122 \\
(33-312)\end{array}$ & $\begin{array}{l}391 \\
(107-1001)\end{array}$ \\
\hline $\begin{array}{l}\text { Total patients with } \\
\text { neurological disease } \\
\text { (proportion of total } \\
\text { coronavirus cases } \\
{[95 \% \mathrm{CI}] \text { ) }}\end{array}$ & $\begin{array}{l}7(0.09 \% \\
[0.03-0 \cdot 18])\end{array}$ & $\begin{array}{l}9(0.36 \% \\
[0.16-0.68])\end{array}$ & $\begin{array}{l}4213 \\
(1028-11440)\end{array}$ & $\begin{array}{l}17408 \\
(5252-42326)\end{array}$ & $\begin{array}{l}73 \\
(18-198)\end{array}$ & $\begin{array}{l}302 \\
(91-734)\end{array}$ & $\begin{array}{l}1266 \\
(309-3438)\end{array}$ & $\begin{array}{l}5231 \\
(1578-12720)\end{array}$ & $\begin{array}{l}213 \\
(52-579)\end{array}$ & $\begin{array}{l}880 \\
(266-2141)\end{array}$ \\
\hline
\end{tabular}

For the Johns Hopkins COVID-19 Dashboard see https://coronavirus.jhu.edu/ map.html in the third. ${ }^{8}$ Four patients with severe SARS developed neuromuscular disease, predominantly motor neuropathy, myopathy, or both, ${ }^{9}$ which might have been SARSspecific or secondary to critical illness. ${ }^{10} \mathrm{CNS}$ involvement was described for five adults with MERS; two had acute disseminated encephalomyelitis, two had cerebrovascular disease, and one had Bickerstaff's brainstem encephalitis. $^{11-13}$ Neuropathy was described in three patients. ${ }^{11,13}$ Human coronavirus OC43, a seasonal coronavirus, has caused encephalitis in an infant with severe combined immunodeficiency, ${ }^{14}$ and acute disseminated encephalomyelitis in an older immunocompetent child. ${ }^{15}$ Headache, neck stiffness, and seizures were described among 22 children (median age 36 months; range $0 \cdot 8-72$ months) with suspected CNS infection and coronavirus IgM antibodies in their serum, CSF, or both. ${ }^{16}$ Ten of these children had pleiocytosis and eight had brain imaging abnormalities. All 22 made a full recovery. ${ }^{16}$

Neurological complications have also been described for other respiratory viruses, particularly seasonal and pandemic influenza. ${ }^{3}$ These complications include acute necrotising encephalopathy (associated with mutations in the RANBP2 gene), acute infantile encephalopathy, and acute haemorrhagic leukoencephalopathy and myelopathy in adults. ${ }^{17,18}$ The estimated incidence of neurological disorders during the 2009 influenza A H1N1 pandemic was 1.2 per 100000 , with children affected more than adults. ${ }^{19-22}$ The 1918 H1N1 influenza pandemic has been associated with post-infectious encephalitis lethargica, although a causative link has not been proven. ${ }^{23}$

\section{Projected epidemiology of COVID-19-associated neurological disease}

Although neurological complications are rare in SARS, MERS, and COVID-19, the scale of the current pandemic means that even a small proportion could build up to a large number of cases. The minimum prevalence of CNS complications ranged from $0 \cdot 04 \%$ for SARS to $0 \cdot 20 \%$ for MERS, and PNS complications ranged from $0.05 \%$ for SARS to $0 \cdot 16 \%$ for MERS, from which we have extrapolated the number of cases with neurological complications of COVID-19 (table 1). Given the 4.8 million cases of COVID-19 globally, these prevalences project to a total of 1805-9671 patients with CNS complications and 2407-7737 with PNS complications. These numbers, which do not include the increasingly important syndromes of stroke-associated COVID-19 infection, will rise as the pandemic continues.

\section{Clinical features of COVID-19-associated neurological disease}

As the COVID-19 pandemic progresses, reports of neurological manifestations are increasing; to date, 901 patients have been reported. These manifestations can be considered as direct effects of the virus on the nervous system, para-infectious or post-infectious immune-mediated disease, and neurological complications of the systemic effects of COVID-19 (appendix p 4). In one national registry of 125 patients with COVID-19 and neurological or psychiatric disease reported over a 3 -week period, ${ }^{25} 39(31 \%)$ patients had altered mental status, which included 16 (13\%) with encephalopathy (of whom seven [6\%] had encephalitis), and $23(18 \%)$ with a neuropsychiatric diagnosis, including ten $(8 \%)$ with psychosis, six $(5 \%)$ with neurocognitive (dementia-like) syndrome, and four (3\%) with an affective disorder. Notably, 77 (62\%) patients had a cerebrovascular event: 57 (46\%) ischaemic strokes, nine (7\%) intracerebral haemorrhages, one $(<1 \%)$ CNS vasculitis, and ten $(8 \%)$ other cerebrovascular events. ${ }^{25}$ The challenges in managing patients with a highly contagious infection, and 
Panel: Provisional case definitions for the association of COVID-19 with neurological disease

\section{WHO COVID-19 case definitions ${ }^{26}$ \\ Confirmed}

A person with laboratory confirmation ${ }^{27}$ of SARS-CoV-2 infection, irrespective of clinical signs and symptoms; confirmatory tests include a nucleic acid amplication test (eg, RT-PCR) or validated antibody test; in an area with established circulation of virus, there should be one positive RT-PCR test or identification of virus on sequencing (one or more negative tests do not rule out infection if there is clinical suspicion); and in an area without established circulation of virus, there should be one positive RT-PCR test for two different viral genome targets or one positive result with partial or whole genome sequencing

Probable

(1) A suspect case for whom testing for the COVID-19 virus is inconclusive; or (2) a suspect case for whom testing could not be done for any reason

Suspected

(1) A patient with acute respiratory illness (fever and at least one sign or symptom of respiratory distress) and history of travel to or residence in a location reporting community transmission of COVID-19 disease during the 14 days before onset; or (2) a patient with acute respiratory illness who has been in contact with a confirmed or probable case in the last 14 days before symptom onset; or (3) a patient with severe acute respiratory illness that requires hospitalisation, and in the absence of an alternative explanation that fully explains the clinical presentation

\section{SARS-CoV-2 meningitis, encephalitis, myelitis, or CNS vasculitis*}

Confirmed

(1) SARS-CoV-2 detected in CSF or brain tissuet or evidence of SARS-CoV-2-specific intrathecal antibody; and (2) no other explanatory pathogen or cause found

Probable

(1) SARS-CoV-2 detected in respiratory or other non-CNS sample, $\neq$ or evidence of SARS-CoV-2-specific antibody in serum indicating acute infection; $\$$ and (2) no other explanatory pathogen or cause found

\section{Possible}

Patient meets suspected case definition of COVID-19 according to national or WHO guidance on the basis of clinical symptoms and epidemiological risk factors; in the context of known community SARS-CoV-2 transmission, supportive features include the following: the new onset of at least one of cough, fever, muscle aches, loss of smell, or loss of taste; lymphopenia or raised D-dimer level; and radiological evidence of abnormalities consistent with infection or inflammation (eg, ground glass changes)

Acute disseminated encephalomyelitis* associated with SARS-CoV-2 infection, Guillain-Barré syndrome, ${ }^{*}$ and other acute neuropathies associated with SARS-CoV-2 infection Probable association

(1) Neurological disease onset within 6 weeks of acute infection; and (2) either SARS-CoV-2 RNA detected in any sample or antibody evidence of acute SARS-CoV-2 infection; and (3) no evidence of other commonly associated causes

Possible association

(1) Neurological disease onset within 6 weeks of acute infection; and (2) either SARS-CoV-2 RNA detected in any sample or antibody evidence of acute SARS-CoV-2 infection and (3) evidence of other commonly associated causes $\boldsymbol{\Psi}$

Stroke* associated with SARS-CoV-2 infection Probable association

(1) Either SARS-CoV-2 detected in CSF or other sample, $\neq$ or evidence of SARS-CoV-2-specific antibody in serum indicating acute infection; and (2) no other known traditional cardiovascular risk factors\|

Possible association

(1) Either SARS-CoV-2 detected in CSF or other sample, or evidence of SARS-CoV-2-specific antibody indicating acute infection; and (2) other traditional cardiovascular risk factors ||

These case definitions are suggestions based on published information to date; they are likely to need refining as more data emerge. The terms confirmed, probable, and suspected are used in the WHO COVID-19 case definitions; the terms confirmed, probable, possible, probable association, and possible association reflect the terminology used for the different syndromes in the original publications from which this panel derives. ${ }^{28-30}$ SARS-CoV-2=severe acute respiratory syndrome coronavirus $2 .{ }^{*}$ Definitions for the different neurological diseases and syndromes are in the appendix ( $\mathrm{pp} 5-12$ ). †Detection in CSF or brain tissue by PCR, culture, or immunohistochemistry, as appropriate. $\ddagger$ Detection in non-CNS sample by PCR or culture. SSerological evidence of acute infection can be defined as detection of IgM, IgG seroconversion, or an increase of four times in antibody titres in paired acute and convalescent serum samples. IThese include infection with one of Campylobacter jejuni, Mycoplasma pneumoniae, Cytomegalovirus, Epstein-Barr virus, hepatitis E virus, Zika virus, or HIV; or vaccination in the last 6 weeks. Associated causes might differ depending on geographical location. ||Traditional cardiovascular risk factors include hypertension, current smoker, diabetes, hypercholesterolaemia, and atrial fibrillation.

\section{Encephalitis}

Encephalitis is the inflammation of the brain parenchyma, usually caused by an infection or the body's immune defences. Although it is strictly speaking a pathological diagnosis, for practical purposes, clinical evidence of brain inflammation is accepted, such as a CSF pleiocytosis, imaging changes, or focal abnormalities on EEG. Detection of virus in the CSF per se does not provide a diagnosis of encephalitis if there is no evidence of brain inflammation (panel; appendix p 6). ${ }^{57}$ 


\begin{tabular}{|c|c|c|c|c|c|c|}
\hline & Clinical presentation & $\begin{array}{l}\text { SARS-CoV-2 } \\
\text { diagnostics }\end{array}$ & $\begin{array}{l}\text { Other pathogen and } \\
\text { antibody } \\
\text { investigations }\end{array}$ & $\begin{array}{l}\text { Relevant blood tests and } \\
\text { radiology findings }\end{array}$ & $\begin{array}{l}\text { Neurological investigations } \\
\text { (CSF findings, neuroimaging, } \\
\text { neurophysiology) }\end{array}$ & $\begin{array}{l}\text { Management, progress, and } \\
\text { outcome }\end{array}$ \\
\hline \multicolumn{7}{|l|}{ CNS disease } \\
\hline \multicolumn{7}{|l|}{ Encephalitis } \\
\hline $\begin{array}{l}\text { Moriguchi et al; }{ }^{31} \\
\text { one case, Japan }\end{array}$ & $\begin{array}{l}\text { Man aged } 24 \text { years, } \\
9 \text { days of fatigue, } \\
\text { headache, fever, sore } \\
\text { throat; then generalised } \\
\text { seizures, reduced } \\
\text { consciousness, and } \\
\text { meningism }\end{array}$ & $\begin{array}{l}\text { RT-PCR was } \\
\text { negative in } \\
\text { nasopharyngeal } \\
\text { swab; positive } \\
\text { in CSF }\end{array}$ & $\begin{array}{l}\text { Serum: anti-HSV-1 and } \\
\text { VZV IgM antibodies } \\
\text { tests were negative }\end{array}$ & $\begin{array}{l}\text { Increased blood white cell } \\
\text { count, neutrophil dominant, } \\
\text { relatively decreased } \\
\text { lymphocytes, increased CRP; } \\
\text { chest CT: small ground glass } \\
\text { opacity in right upper zone } \\
\text { and bilaterally in lower zones }\end{array}$ & $\begin{array}{l}\text { CSF: clear, colourless, } \\
\text { raised opening pressure } \\
\left(320 \mathrm{~mm} \mathrm{H}_{2} 0\right) \text { and cell count } \\
\left(12 / \mathrm{mm}^{3} \text {; ten mononuclear }\right. \\
\text { and two polymorphonuclear } \\
\text { cells); head CT: no brain } \\
\text { oedema; brain MRI: } \\
\text { hyperintensity along wall of } \\
\text { right lateral ventricle on } \\
\text { diffusion-weighted imaging, } \\
\text { and hyperintense signal in } \\
\text { right medial temporal lobe } \\
\text { and hippocampus on } \\
\text { T2-weighted images }\end{array}$ & $\begin{array}{l}\text { Treated empirically for } \\
\text { bacterial pneumonia and viral } \\
\text { encephalitis; on admission, } \\
\text { required intubation and } \\
\text { mechanical ventilation } \\
\text { because of seizures; admitted } \\
\text { to ICU; still on intensive care } \\
\text { at time of report (day 15) }\end{array}$ \\
\hline $\begin{array}{l}\text { Sohal et al:;32 } \\
\text { one case, USA }\end{array}$ & $\begin{array}{l}\text { Man aged } 72 \text { years with } \\
\text { weakness and light } \\
\text { headedness following a } \\
\text { hypoglycaemic episode; } \\
\text { shortly after admission } \\
\text { he had difficulty } \\
\text { breathing and altered } \\
\text { mental status; on day } 2 \\
\text { of admission he started } \\
\text { to have seizures }\end{array}$ & $\begin{array}{l}\text { RT-PCR was } \\
\text { positive; source not } \\
\text { specified }\end{array}$ & $\begin{array}{l}\text { Blood: culture was } \\
\text { negative for bacterial } \\
\text { growth; influenza PCR } \\
\text { was negative }\end{array}$ & $\begin{array}{l}\text { Arterial blood gas test: } \\
\mathrm{pH} 7 \cdot 13, \mathrm{PaO}_{2} 68 \mathrm{~mm} \mathrm{Hg} \text {, } \\
\mathrm{PCO}_{2} 78 \mathrm{~mm} \mathrm{Hg} \text {, raised brain } \\
\text { natriuretic peptide, troponin, } \\
\mathrm{CRP}, \mathrm{LDH} \text {; lymphopenia, and } \\
\text { leucopenia; chest } x \text {-ray: } \\
\text { normal; chest } \mathrm{CT} \text { : bibasilar } \\
\text { opacities along with right } \\
\text { lower lobe consolidation }\end{array}$ & $\begin{array}{l}\text { Head CT: no acute changes, } \\
\text { chronic microvascular } \\
\text { ischaemic changes; } 24 \text {-h EEG: } \\
\text { six left temporal seizures and } \\
\text { left temporal sharp waves } \\
\text { that were epileptogenic }\end{array}$ & $\begin{array}{l}\text { Required intubation and } \\
\text { ventilation and was admitted } \\
\text { to ICU; became hypotensive } \\
\text { requiring norepinephrine } \\
\text { via central line; } \\
\text { hydroxychloroquine and } \\
\text { azithromycin were started in } \\
\text { addition to vancomycin and } \\
\text { piperacillin tazobactam; after } \\
\text { onset of seizures, treated with } \\
\text { levetiracetam and valproate } \\
\text { but they were not controlled; } \\
\text { died on day } 5 \text { of illness }\end{array}$ \\
\hline $\begin{array}{l}\text { Wong et al; }{ }_{r}^{33} \\
\text { one case, UK }\end{array}$ & $\begin{array}{l}\text { Man aged } 40 \text { years with } \\
\text { ataxia, diplopia, } \\
\text { oscillopsia, and bilateral } \\
\text { facial weakness } \\
\text { (rhombencephalitis); } \\
13 \text { days before he had } \\
\text { fever and progressive } \\
\text { shortness of breath on } \\
\text { exertion, followed } \\
10 \text { days later by a } \\
\text { productive cough } \\
\text { and diarrhoea }\end{array}$ & $\begin{array}{l}\text { RT-PCR was } \\
\text { positive in } \\
\text { nasopharyngeal } \\
\text { swab; CSF RT-PCR } \\
\text { was not done }\end{array}$ & $\begin{array}{l}\text { Blood: negative for } \\
\text { hepatitis A, B, and C, } \\
\text { HIV-1 and HIV-2, and } \\
\text { syphilis antibody; CSF: } \\
\text { bacterial culture was } \\
\text { negative; anti- } \\
\text { MOG-IgG antibody and } \\
\text { anti-aquaporin } 4 \\
\text { antibody test results } \\
\text { not reported }\end{array}$ & $\begin{array}{l}\text { Normal white cell count but } \\
\text { lymphopenia; raised CRP and } \\
\text { abnormal raised liver } \\
\text { function tests; chest x-ray: } \\
\text { right lower zone } \\
\text { consolidation; liver } \\
\text { ultrasound: inflammatory } \\
\text { diffusely hypoechoic liver } \\
\text { with raised periportal and } \\
\text { pericholecystic echogenicity }\end{array}$ & $\begin{array}{l}\text { Normal cell count and protein } \\
(0.42 \mathrm{~g} / \mathrm{L}) \text {; brain } \mathrm{MRI} \text { : } \\
\text { increased signal lesion in right } \\
\text { inferior cerebellar peduncle } \\
\text { extending to involve a small } \\
\text { portion of the upper cord } \\
\text { (lesion } 13 \mathrm{~mm} \text { in maximum } \\
\text { cross-sectional area and } \\
28 \mathrm{~mm} \text { in longitudinal } \\
\text { extent); swelling at the } \\
\text { affected tissue and associated } \\
\text { micro-haemorrhage }\end{array}$ & $\begin{array}{l}\text { Treated with oral amoxicillin, } \\
\text { but no other treatment; } \\
\text { gradual improvement in } \\
\text { neurological symptoms; } \\
\text { discharged home after } 11 \text { days } \\
\text { on gabapentin; oscillopsia and } \\
\text { ataxia persisted }\end{array}$ \\
\hline \multicolumn{7}{|c|}{ Other encephalopathies } \\
\hline \multirow[t]{2}{*}{$\begin{array}{l}\text { Dugue et al;;4 } \\
\text { one case, USA }\end{array}$} & $\begin{array}{l}\text { Infant aged } 6 \text { weeks with } \\
\text { cough, fever, and } \\
\text { episodes of bilateral leg } \\
\text { stiffening and sustained } \\
\text { upward gaze }\end{array}$ & $\begin{array}{l}\text { RT-PCR was } \\
\text { positive and } \\
\text { high-throughput } \\
\text { sequencing } \\
\text { detected viral RNA } \\
\text { in nasopharyngeal } \\
\text { and anal swabs; } \\
\text { RT-PCR was } \\
\text { negative in plasma } \\
\text { and CSF }\end{array}$ & $\begin{array}{l}\text { Nasopharyngeal sample } \\
\text { tested for respiratory } \\
\text { pathogen; PCR panel } \\
\text { positive for rhinovirus- } \\
\text { enterovirus; } \\
\text { high-throughput } \\
\text { sequencing was } \\
\text { positive for rhinovirus } \\
\text { C; CSF: meningitis- } \\
\text { encephalitis pathogen } \\
\text { PCR panel was negative; } \\
\text { culture negative }\end{array}$ & $\begin{array}{l}\text { Leucopenia }\left(5 \cdot 07 \times 10^{3} \text { white }\right. \\
\text { blood cells per } \mu \mathrm{L}) \text { with a } \\
\text { normal differential, and } \\
\text { elevated procalcitonin of } \\
0.21 \mathrm{ng} / \mathrm{m} \text {; normal urea and } \\
\text { electrolytes }\end{array}$ & $\begin{array}{l}\text { CSF: normal; brain MRI: } \\
\text { normal; prolonged EEG } \\
\text { monitoring: excess of } \\
\text { temporal sharp transients and } \\
\text { intermittent vertex delta, } \\
\text { slowing with normal } \\
\text { sleep-wake cycling }\end{array}$ & $\begin{array}{l}\text { No specific treatment; } \\
\text { no further episodes and } \\
\text { discharged home after } 1 \text { day }\end{array}$ \\
\hline & & & & & & Table 2 continues on next page) \\
\hline
\end{tabular}

As of May 19, 2020, eight adults aged 24-78 years (median 62 [IQR 40-70]), including four women, have been described with encephalitis associated with COVID-19, mostly diagnosed through a nasal or nasopharyngeal swab (table 2; appendix pp 13-14). .1-33,58-61 $^{\text {Neurological features }}$ mostly started from the time of respiratory symptom onset to 17 days afterwards, although in one man aged 60 years, confusion preceded cough and fever by two days (figure 1 ). ${ }^{58}$ Two patients had fever only, with no respiratory features..$^{59,60}$ The neurological manifestations were typical for encephalitis, with irritability, confusion, and reduced consciousness, sometimes associated with seizures; three patients also had neck stiffness ${ }^{31,58,59}$ and another had psychotic symptoms. ${ }^{61}$ A man aged 40 years developed ataxia, oscillopsia, hiccups, 


\begin{tabular}{|c|c|c|c|c|c|c|}
\hline & Clinical presentation & $\begin{array}{l}\text { SARS-CoV-2 } \\
\text { diagnostics }\end{array}$ & $\begin{array}{l}\text { Other pathogen and } \\
\text { antibody } \\
\text { investigations }\end{array}$ & $\begin{array}{l}\text { Relevant blood tests and } \\
\text { radiology findings }\end{array}$ & $\begin{array}{l}\text { Neurological investigations } \\
\text { (CSF findings, neuroimaging, } \\
\text { neurophysiology) }\end{array}$ & $\begin{array}{l}\text { Management, progress, and } \\
\text { outcome }\end{array}$ \\
\hline \multicolumn{7}{|c|}{ (Continued from previous page) } \\
\hline $\begin{array}{l}\text { Poyiadji et al;:37 } \\
\text { one case, USA }\end{array}$ & $\begin{array}{l}\text { Female patient with } \\
\text { cough, fever, and altered } \\
\text { mental status; imaging } \\
\text { consistent with acute } \\
\text { necrotising } \\
\text { encephalopathy }\end{array}$ & $\begin{array}{l}\text { RT-PCR was } \\
\text { positive in } \\
\text { nasopharyngeal } \\
\text { swab; CSF RT-PCR } \\
\text { not done }\end{array}$ & $\begin{array}{l}\text { CSF: bacterial culture } \\
\text { negative after } 3 \text { days } \\
\text { and tests for HSV, VZV, } \\
\text { and WNV were } \\
\text { negative }\end{array}$ & NR & $\begin{array}{l}\text { Non-contrast head CT: } \\
\text { symmetric hypoattenuation } \\
\text { in bilateral medial thalami; } \\
\text { brain MRI: T2 FLAIR } \\
\text { hyperintensity in bilateral } \\
\text { medial temporal lobes, } \\
\text { thalami, and subinsular } \\
\text { regions, and evidence of } \\
\text { haemorrhage indicated by } \\
\text { hypointensity on } \\
\text { susceptibility-weighted } \\
\text { images and rim enhancement } \\
\text { on post-contrast images }\end{array}$ & $\begin{array}{l}\text { Treated with intravenous } \\
\text { immunoglobulin; outcome } \\
\text { not reported }\end{array}$ \\
\hline $\begin{array}{l}\text { Zhou et al }{ }^{39} \\
\text { one case, China }\end{array}$ & $\begin{array}{l}\text { Patient aged } 56 \text { years } \\
\text { with COVID-19 } \\
\text { pneumonia }\end{array}$ & $\begin{array}{l}\text { SARS-CoV2 } \\
\text { detected by } \\
\text { sequencing in CSF }\end{array}$ & NR & NR & NR & $\mathrm{NR}$ \\
\hline
\end{tabular}

and bilateral facial weakness. ${ }^{33}$ CSF analysis was reported for six patients; it showed a pleiocytosis in five, mostly lymphocytic, and was normal in one patient. Four patients had CSF PCR done for SARS-CoV-2, of whom one was positive: a man aged 24 years with encephalitis, minor respiratory symptoms, and ground glass changes on chest CT, who had a PCR negative respiratory sample. ${ }^{31}$ Few publications reported comprehensive investigation for other causes of encephalitis (table 2; appendix pp 13-14). Brain imaging was normal or had no acute changes for six patients, and showed high signal intensity in two, including temporal lobe changes in one (figure $2 \mathrm{~A}, \mathrm{~B}$ ); ${ }^{31}$ the patient with ataxia had a cerebellar lesion that extended into the spinal cord. ${ }^{33}$ EEG was done in five patients..$^{32,58-61}$ Two had 


\begin{tabular}{|c|c|c|c|c|c|c|}
\hline & Clinical presentation & $\begin{array}{l}\text { SARS-CoV-2 } \\
\text { diagnostics }\end{array}$ & $\begin{array}{l}\text { Other pathogen and } \\
\text { antibody } \\
\text { investigations }\end{array}$ & $\begin{array}{l}\text { Relevant blood tests and } \\
\text { radiology findings }\end{array}$ & $\begin{array}{l}\text { Neurological investigations } \\
\text { (CSF findings, neuroimaging, } \\
\text { neurophysiology) }\end{array}$ & $\begin{array}{l}\text { Management, progress, and } \\
\text { outcome }\end{array}$ \\
\hline \multicolumn{7}{|c|}{ (Continued from previous page) } \\
\hline \multicolumn{7}{|c|}{ Acute disseminated encephalomyelitis } \\
\hline $\begin{array}{l}\text { Zanin et al; }{ }^{40} \\
\text { one case, Italy }\end{array}$ & $\begin{array}{l}\text { Woman aged } 54 \text { years } \\
\text { presented with } \\
\text { agitation, decreased } \\
\text { consciousness, and } \\
\text { seizures following } \\
\text { several days of anosmia } \\
\text { and ageusia }\end{array}$ & $\begin{array}{l}\text { RT-PCR was } \\
\text { positive in } \\
\text { respiratory sample }\end{array}$ & $\begin{array}{l}\text { Blood: cultures were } \\
\text { negative; urine: } \\
\text { cultures were negative }\end{array}$ & $\begin{array}{l}\text { Lymphopenia }\left(0 \cdot 3 \times 10^{9} \text { cells }\right. \\
\text { per } \mathrm{L}) \text { with mild elevation of } \\
\text { inflammatory markers } \\
(\mathrm{CRP} 41 \cdot 3 \mathrm{mg} / \mathrm{L} \text {, fibrinogen } \\
520 \mathrm{mg} / \mathrm{dL}) \text {; chest } \mathrm{x} \text {-ray: } \\
\text { interstitial pneumonia }\end{array}$ & $\begin{array}{l}\text { CSF: normal; brain and spine } \\
\text { MRI: periventricular confluent } \\
\text { white matter lesions and } \\
\text { numerous high signal cord } \\
\text { lesions from bulbomedullary } \\
\text { junction to T6 level; no } \\
\text { contrast enhancement }\end{array}$ & $\begin{array}{l}\text { Treated with antiretrovirals } \\
\text { and hydroxychloroquine; } \\
\text { clinically deteriorated } \\
\text { becoming hypoxic, requiring } \\
\text { intubation and mechanical } \\
\text { ventilation; treated with high } \\
\text { dose dexamethasone; } \\
\text { tracheostomy done on day } 7 ; \\
\text { weaned off ventilator on } \\
\text { day } 15 \text {; discharged and } \\
\text { transferred to rehabilitation } \\
\text { without sensorimotor deficit } \\
\text { about } 1 \text { month after admission }\end{array}$ \\
\hline $\begin{array}{l}\text { Zhang et al; }{ }^{41} \\
\text { one case, USA }\end{array}$ & $\begin{array}{l}\text { Woman in early } 40 \text { s with } \\
\text { a 9-day history of } \\
\text { headache and myalgia } \\
\text { presented with } \\
\text { dysphagia, dysarthria, } \\
\text { expressive dysphasia, } \\
\text { and encephalopathy; } \\
\text { left sided facial } \\
\text { weakness, fever, and } \\
\text { dyspnoea on admission }\end{array}$ & $\begin{array}{l}\text { RT-PCR was } \\
\text { positive; site not } \\
\text { specified } \\
\text { (presumed } \\
\text { respiratory sample) }\end{array}$ & $\begin{array}{l}\text { Negative influenza } \\
\text { swab and negative } \\
\text { rapid streptococcus } \\
\text { test; CSF: negative; } \\
\text { PCR test for HSV-1 } \\
\text { and HSV-2, HHV-6, } \\
\text { and VZV, and negative } \\
\text { Cryptococcus test; } \\
\text { bacterial cultures were } \\
\text { negative }\end{array}$ & $\begin{array}{l}\text { Mild leukocytosis with } \\
\text { lymphopenia; chest x-ray: } \\
\text { patchy consolidation in right } \\
\text { lower lung }\end{array}$ & $\begin{array}{l}\text { CSF: normal cell count, } \\
\text { protein, and glucose; brain } \\
\text { MRI: extensive areas of } \\
\text { high signal in bilateral } \\
\text { frontoparietal white matter, } \\
\text { anterior temporal lobes, basal } \\
\text { ganglia, external capsules, and } \\
\text { thalami; some foci showed } \\
\text { diffusion-weighted imaging } \\
\text { changes and corresponding } \\
\text { apparent diffusion coefficient } \\
\text { changes; brain and neck } \\
\text { magnetic resonance } \\
\text { angiography: normal; EEG: } \\
\text { no evidence of seizures }\end{array}$ & $\begin{array}{l}\text { Treated with } \\
\text { hydroxychloroquine, } \\
\text { ceftriaxone, and intravenous } \\
\text { immunoglobulin; some } \\
\text { improvement in dysphagia } \\
\text { and dysarthria after } 5 \text { days }\end{array}$ \\
\hline \multicolumn{7}{|l|}{ Myelitis } \\
\hline $\begin{array}{l}\text { Zhao et al; } 42 \\
\text { one case, China }\end{array}$ & $\begin{array}{l}\text { Man aged } 66 \text { years } \\
\text { admitted with fever, } \\
\text { dyspnoea, and asthma; } \\
5 \text { days after respiratory } \\
\text { symptom onset, } \\
\text { developed acute flaccid } \\
\text { paralysis of lower limbs, } \\
\text { urinary and faecal } \\
\text { incontinence, and a } \\
\text { sensory level at T10 }\end{array}$ & $\begin{array}{l}\text { RT-PCR was } \\
\text { positive in } \\
\text { nasopharyngeal } \\
\text { swab }\end{array}$ & $\begin{array}{l}\text { Blood: negative for } \\
\text { EBV, influenza A, } \\
\text { influenza B, } \\
\text { adenovirus, } \\
\text { coxsackievirus, } \\
\text { parainfluenza virus, } \\
\text { CMV, and RSV on } \\
\text { serum IgM testing; } \\
\text { negative for } \\
\text { Chlamydia pneumoniae, } \\
\text { Mycoplasma } \\
\text { pneumoniae, and } \\
\text { tuberculosis }\end{array}$ & $\begin{array}{l}\text { Lymphopenia } \\
\left(0.55 \times 10^{9} \text { cells per } \mathrm{L}\right) \text { and } \\
\text { raised } \mathrm{CRP}(277 \mathrm{mg} / \mathrm{L}) \\
\text { and procalcitonin } \\
(4.33 \mathrm{ng} / \mathrm{mL}) \text {; slightly raised } \\
\text { alanine aminotransferase } \\
(56 \mathrm{U} / \mathrm{L}) \text { and aspartate } \\
\text { aminotransferase }(50 \mathrm{U} / \mathrm{L}) \text {; } \\
\text { chest } \mathrm{CT} \text { : bilateral patchy } \\
\text { changes }\end{array}$ & $\begin{array}{l}\text { Brain CT: lacunar infarcts; } \\
\text { spinal imaging not done }\end{array}$ & $\begin{array}{l}\text { On admission, deteriorated } \\
\text { rapidly and admitted to ICU; } \\
\text { treated with moxifloxacin, } \\
\text { oseltamivir, lopinavir- } \\
\text { ritonavir, ganciclovir, and } \\
\text { meropenem, followed by } \\
\text { dexamethasone and } \\
\text { intravenous immunoglobulin } \\
\text { for neurological symptoms; } \\
\text { required oxygen; slight } \\
\text { improvement in power in } \\
\text { upper and lower limbs } \\
\text { following treatment, but still } \\
\text { unable to walk; discharged } \\
\text { and transferred for } \\
\text { rehabilitation }\end{array}$ \\
\hline \multicolumn{7}{|c|}{ Peripheral nervous system disease } \\
\hline \multicolumn{7}{|c|}{ Guillain-Barré syndrome } \\
\hline $\begin{array}{l}\text { Camdessanche } \\
\text { et al; }{ }^{43} \text { one case, } \\
\text { France }\end{array}$ & $\begin{array}{l}\text { Man aged } 64 \text { years with } \\
2 \text { days of cough and } \\
\text { fever presented } \\
\text { following a fall; on day } 9 \\
\text { of hospital admission, } \\
\text { developed paraesthesia } \\
\text { in hands and feet and } \\
\text { progressive weakness in } \\
\text { all limbs, with areflexia } \\
\text { and loss of vibration } \\
\text { sense; then developed } \\
\text { dysphagia and } \\
\text { respiratory insufficiency }\end{array}$ & $\begin{array}{l}\text { RT-PCR was } \\
\text { positive in } \\
\text { nasopharyngeal } \\
\text { swab on admission, } \\
9 \text { days before onset } \\
\text { of neurological } \\
\text { symptoms }\end{array}$ & $\begin{array}{l}\text { Negative for } \\
\text { Campylobacter jejuni, } \\
\text { M pneumoniae, } \\
\text { Salmonella enterica, } \\
\text { CMV, EBV, HSV-1, } \\
\text { HSV-2, VZV, influenza } \\
\text { virus A and B, HIV, and } \\
\text { hepatitis E; serum: } \\
\text { antiganglioside } \\
\text { antibodies not } \\
\text { detected }\end{array}$ & $\begin{array}{l}\text { Chest CT: } 10 \% \text { to } 25 \% \\
\text { ground glass opacities }\end{array}$ & $\begin{array}{l}\text { CSF: normal cell count and } \\
\text { raised protein ( } 166 \mathrm{mg} / \mathrm{dL}) \text {; } \\
\text { nerve conduction study and } \\
\text { electromyography: acute } \\
\text { inflammatory demyelinating } \\
\text { polyneuropathy }\end{array}$ & $\begin{array}{l}\text { Had initially needed } 2 \mathrm{~L} \text { to } 3 \mathrm{~L} \\
\text { oxygen via nasal cannula but } \\
\text { had been weaned off it before } \\
\text { onset of neurological } \\
\text { symptoms; given lopinavir- } \\
\text { ritonavir; treated with } \\
\text { intravenous immunoglobulin } \\
\text { for } 5 \text { days; developed } \\
\text { respiratory insufficiency and } \\
\text { required admission to ICU for } \\
\text { intubation and mechanical } \\
\text { ventilation; no other } \\
\text { details given }\end{array}$ \\
\hline & & & & & & (Table 2 continues on next page) \\
\hline
\end{tabular}




\begin{tabular}{|c|c|c|c|c|c|c|}
\hline & Clinical presentation & $\begin{array}{l}\text { SARS-CoV-2 } \\
\text { diagnostics }\end{array}$ & $\begin{array}{l}\text { Other pathogen and } \\
\text { antibody } \\
\text { investigations }\end{array}$ & $\begin{array}{l}\text { Relevant blood tests and } \\
\text { radiology findings }\end{array}$ & $\begin{array}{l}\text { Neurological investigations } \\
\text { (CSF findings, neuroimaging, } \\
\text { neurophysiology) }\end{array}$ & $\begin{array}{l}\text { Management, progress, and } \\
\text { outcome }\end{array}$ \\
\hline \multicolumn{7}{|c|}{ (Continued from previous page) } \\
\hline $\begin{array}{l}\text { Toscano et al;; } \\
\text { five cases, Italy }\end{array}$ & $\begin{array}{l}\text { Five patients (four men } \\
\text { and one woman), aged } \\
23 \text { to } 77 \text { years; four } \\
\text { patients had flaccid, } \\
\text { areflexic limb weakness } \\
\text { (three with quadriparesis } \\
\text { and one with } \\
\text { paraparesis), three of } \\
\text { whom had facial } \\
\text { weakness, two had } \\
\text { dysphagia, and three } \\
\text { developed respiratory } \\
\text { failure; one had facial } \\
\text { diplegia, areflexia, limb } \\
\text { paraesthesia, and ataxia; } \\
\text { patients presented } \\
\text { a median of } 7 \\
\text { (range } 5 \text { to } 10 \text { ) days after } \\
\text { respiratory symptoms; } \\
\text { four had cough, } \\
\text { three had fever, three had } \\
\text { hyposmia, anosmia, or } \\
\text { ageusia, and one had } \\
\text { pharyngitis }\end{array}$ & $\begin{array}{l}\text { RT-PCR was } \\
\text { positive in } \\
\text { nasopharyngeal } \\
\text { swab of four } \\
\text { patients; one } \\
\text { patient was } \\
\text { positive by } \\
\text { serological test; } \\
\text { RT-PCR in CSF was } \\
\text { negative in } \\
\text { all patients }\end{array}$ & $\begin{array}{l}\text { One patient (patient 5) } \\
\text { was negative for C } \\
\text { jejuni, EBV, CMV, HSV, } \\
\text { VZV, influenza, and } \\
\text { HIV; three patients } \\
\text { were tested for } \\
\text { antiganglioside } \\
\text { antibodies, but none } \\
\text { was detected }\end{array}$ & $\begin{array}{l}\text { Patient 1: CT scan of thorax } \\
\text { showed interstitial bilateral } \\
\text { pneumonia; patient 2: no } \\
\text { details; patient 3: CT scan of } \\
\text { thorax showed multiple } \\
\text { bilateral, ground glass } \\
\text { opacities compatible with } \\
\text { interstitial pneumonia; } \\
\text { patient 4: chest imaging was } \\
\text { negative; patient 5: } x \text {-ray and } \\
\text { CT showed interstitial } \\
\text { pneumonia, without } \\
\text { parenchymal opacities or } \\
\text { alveolar damage }\end{array}$ & $\begin{array}{l}\text { CSF analysis: all patients had } \\
\text { normal white cell counts, } \\
\text { three had elevated protein; } \\
\text { MRI: enhancement of caudal } \\
\text { nerve roots in two patients } \\
\text { and of facial nerve in one, and } \\
\text { no signal change in } \\
\text { two patients; nerve } \\
\text { conduction study: axonal } \\
\text { pattern in three patients and } \\
\text { demyelinating in two }\end{array}$ & $\begin{array}{l}\text { All treated with intravenous } \\
\text { immunoglobulin; two had } \\
\text { two cycles, and one also } \\
\text { had plasma exchange; } \\
\text { three required mechanical } \\
\text { ventilation; at } 4 \text { weeks, } \\
\text { two patients were still } \\
\text { ventilated in intensive care, } \\
\text { two were having } \\
\text { physiotherapy, and } \\
\text { one was discharged }\end{array}$ \\
\hline $\begin{array}{l}\text { Zhao et al, } ; 5 \\
\text { one case, China }\end{array}$ & $\begin{array}{l}\text { Woman aged } 61 \text { years } \\
\text { with progressive } \\
\text { weakness of lower and } \\
\text { then upper limbs and } \\
\text { severe fatigue; areflexia } \\
\text { in lower limbs and } \\
\text { decreased sensation } \\
\text { distally; } 7 \text { days after } \\
\text { neurological symptoms, } \\
\text { she developed dry cough } \\
\text { and fever }\end{array}$ & $\begin{array}{l}\text { RT-PCR was } \\
\text { positive in } \\
\text { oropharyngeal } \\
\text { swab }\end{array}$ & NR & $\begin{array}{l}\text { Laboratory results on } \\
\text { admission were clinically } \\
\text { significant for lymphopenia } \\
\text { and thrombocytopenia; } \\
\text { chest CT: ground glass } \\
\text { opacities bilaterally }\end{array}$ & $\begin{array}{l}\text { CSF: normal cell count and } \\
\text { raised protein }(124 \mathrm{mg} / \mathrm{dL}) ; \\
\text { nerve conduction study: acute } \\
\text { inflammatory demyelinating } \\
\text { polyneuropathy }\end{array}$ & $\begin{array}{l}\text { Treated with intravenous } \\
\text { immunoglobulin for } 5 \text { days; } \\
\text { given arbidol, lopinavir, } \\
\text { and ritonavir; improved } \\
\text { neurologically; had normal } \\
\text { power and reflexes on } \\
\text { discharge at day } 30\end{array}$ \\
\hline \multicolumn{7}{|c|}{ GBS variants and other neuropathies } \\
\hline $\begin{array}{l}\text { Gutiérrez-Ortiz } \\
\text { et al; }{ }^{46} \text { one Miller } \\
\text { Fisher Syndrome, } \\
\text { Spain }\end{array}$ & $\begin{array}{l}\text { Man aged } 50 \text { years with } \\
5 \text { days of cough, fever, } \\
\text { malaise, headache, back } \\
\text { pain, anosmia, and } \\
\text { ageusia, who developed } \\
\text { right internuclear } \\
\text { opthalmoparesis with } \\
\text { right fascicular } \\
\text { oculomotor palsy, ataxia, } \\
\text { and areflexia (preserved } \\
\text { plantar responses) }\end{array}$ & $\begin{array}{l}\text { RT-PCR was } \\
\text { positive in } \\
\text { oropharyngeal } \\
\text { swab, negative } \\
\text { in CSF }\end{array}$ & $\begin{array}{l}\text { Antiganglioside } \\
\text { antibody GD1b-lgG } \\
\text { detected in serum; } \\
\text { normal CSF cytology, } \\
\text { sterile cultures, and } \\
\text { negative antibody tests }\end{array}$ & $\begin{array}{l}\text { Lymphopenia; elevated CRP; } \\
\text { chest x-ray: normal }\end{array}$ & $\begin{array}{l}\text { CSF: normal opening pressure, } \\
\text { cell count, raised protein } \\
(80 \mathrm{mg} / \mathrm{dL}) \text {, and normal } \\
\text { glucose; brain CT with } \\
\text { contrast: normal }\end{array}$ & $\begin{array}{l}\text { Treated with intravenous } \\
\text { immunoglobulin for } 5 \text { days; } \\
\text { complete recovery at } 2 \text { weeks } \\
\text { except for residual anosmia } \\
\text { and ageusia }\end{array}$ \\
\hline $\begin{array}{l}\text { Dinkin et al } ;^{47} \text { one } \\
\text { ophthalmoplegia, } \\
\text { USA }\end{array}$ & $\begin{array}{l}\text { Woman aged } 71 \text { years } \\
\text { with isolated } \\
\text { ophthalmoplegia after a } \\
\text { few days of cough and } \\
\text { fever; unable to abduct } \\
\text { her right eye (right } \\
\text { abducens palsy) }\end{array}$ & $\begin{array}{l}\text { RT-PCR was } \\
\text { positive in } \\
\text { nasal swab }\end{array}$ & NR & $\begin{array}{l}\text { Leucopenia; chest x-ray: } \\
\text { bilateral opacities }\end{array}$ & $\begin{array}{l}\text { CSF: normal opening pressure; } \\
\text { brain MRI: enhancement of } \\
\text { optic nerve sheaths and } \\
\text { posterior Tenon capsules }\end{array}$ & $\begin{array}{l}\text { Treated with } \\
\text { hydroxychloroquine and } \\
\text { oxygen; discharged after } \\
6 \text { days; symptoms improving, } \\
\text { although ongoing at } 2 \text { weeks } \\
\text { after discharge }\end{array}$ \\
\hline $\begin{array}{l}\text { Gutiérrez-Ortiz } \\
\text { et al; }{ }^{46} \text { one } \\
\text { bilateral } \\
\text { ophthalmoplegia, } \\
\text { Spain }\end{array}$ & $\begin{array}{l}\text { Man aged } 39 \text { years, with } \\
3 \text { days of fever and } \\
\text { diarrhoea, developed } \\
\text { diplopia; abduction } \\
\text { deficits in both eyes and } \\
\text { fixation nystagmus } \\
\text { consistent with bilateral } \\
\text { abducens palsy; global } \\
\text { areflexia and ageusia }\end{array}$ & $\begin{array}{l}\text { RT-PCR was } \\
\text { positive in } \\
\text { oropharyngeal } \\
\text { swab and negative } \\
\text { in CSF }\end{array}$ & $\begin{array}{l}\text { Normal CSF cytology, } \\
\text { sterile cultures, } \\
\text { and negative } \\
\text { anti-pathogen } \\
\text { antibody tests }\end{array}$ & $\begin{array}{l}\text { Leucopenia, but blood tests } \\
\text { otherwise normal; chest } \\
\text { x-ray: normal }\end{array}$ & $\begin{array}{l}\text { CSF: normal cell count, but } \\
\text { raised protein ( } 62 \mathrm{mg} / \mathrm{dL}) \text {; } \\
\text { brain CT: normal }\end{array}$ & $\begin{array}{l}\text { No specific treatment; } \\
\text { complete recovery in } 2 \text { weeks }\end{array}$ \\
\hline
\end{tabular}




\begin{tabular}{|c|c|c|c|c|c|c|}
\hline & Clinical presentation & $\begin{array}{l}\text { SARS-CoV-2 } \\
\text { diagnostics }\end{array}$ & $\begin{array}{l}\text { Other pathogen and } \\
\text { antibody } \\
\text { investigations }\end{array}$ & $\begin{array}{l}\text { Relevant blood tests and } \\
\text { radiology findings }\end{array}$ & $\begin{array}{l}\text { Neurological investigations } \\
\text { (CSF findings, neuroimaging, } \\
\text { neurophysiology) }\end{array}$ & $\begin{array}{l}\text { Management, progress, and } \\
\text { outcome }\end{array}$ \\
\hline \multicolumn{7}{|c|}{ (Continued from previous page) } \\
\hline $\begin{array}{l}\text { Escalada Pellitero } \\
\text { et al; }{ }^{48} \text { one acute } \\
\text { vestibular } \\
\text { dysfunction, USA }\end{array}$ & $\begin{array}{l}\text { Woman aged } 30 \text { years } \\
\text { had nausea, unsteadiness, } \\
\text { and disequilibrium that } \\
\text { was worse on standing; } \\
3 \text { weeks before, she had } \\
10 \text { days of anosmia and } \\
\text { ageusia; horizontal } \\
\text { nystagmus with rapid } \\
\text { phase to the right, } \\
\text { oscillopsia, and } \\
\text { Romberg positive }\end{array}$ & $\begin{array}{l}\text { RT-PCR was } \\
\text { positive on } \\
\text { admission; sample } \\
\text { tested not reported }\end{array}$ & NR & $\begin{array}{l}\text { Lymphopenia, and raised } \\
\text { D-dimer, fibrinogen, and } \\
\text { CRP; chest CT angiogram: } \\
\text { normal }\end{array}$ & $\begin{array}{l}\text { Brain MRI with contrast: } \\
\text { normal }\end{array}$ & $\begin{array}{l}\text { Treated with antiemetics and } \\
\text { vestibular suppressants; } \\
\text { improved }\end{array}$ \\
\hline \multicolumn{7}{|c|}{ Rhabdomyolysis and other muscle disease } \\
\hline $\begin{array}{l}\text { Jin et al }{ }^{49} \\
\text { one case of } \\
\text { rhabdomyolysis, } \\
\text { China }\end{array}$ & $\begin{array}{l}\text { Man aged } 60 \text { years } \\
\text { admitted with COVID-19 } \\
\text { developed weakness and } \\
\text { tenderness in lower } \\
\text { limbs } 15 \text { days after onset } \\
\text { of fever and cough }\end{array}$ & $\begin{array}{l}\text { RT-PCR was } \\
\text { positive in } \\
\text { throat swab }\end{array}$ & $\begin{array}{l}\text { Urine: blood and } \\
\text { protein detected }\end{array}$ & $\begin{array}{l}\text { Leucopenia, and raised CRP } \\
\text { and LDH; normal urea, } \\
\text { electrolytes, liver function } \\
\text { tests, and creatine kinase } \\
\text { initially; then raised creatine } \\
\text { kinase }(11842 \mathrm{U} / \mathrm{L}), \\
\text { myoglobin }(12000 \mathrm{mg} / \mathrm{L}), \\
\text { aspartate aminotransferase } \\
\text { and alanine } \\
\text { aminotransferase; chest CT: } \\
\text { ground glass opacities }\end{array}$ & NR & $\begin{array}{l}\text { Worsening respiratory status } \\
\text { following admission; received } \\
\text { antibiotics and supportive } \\
\text { therapy; neuromuscular } \\
\text { symptoms improved over } \\
\text { several days }\end{array}$ \\
\hline \multicolumn{7}{|c|}{ Taste and smell dysfunction } \\
\hline $\begin{array}{l}\text { Lechien et al:50 } \\
357 \text { cases, } \\
\text { Belgium, France, } \\
\text { Italy, Spain, and } \\
\text { Switzerland }\end{array}$ & $\begin{array}{l}357(86 \%) \text { of } \\
417 \text { patients had smell } \\
\text { dysfunction; } 342(82 \%) \\
\text { had taste dysfunction }\end{array}$ & $\begin{array}{l}\text { All RT-PCR were } \\
\text { positive in } \\
\text { respiratory samples }\end{array}$ & NR & NR & NR & $\begin{array}{l}\text { Treated with nasal } \\
\text { corticosteroids }(8 \%) \text {, oral } \\
\text { corticosteroids }(3 \%) \text {, and } \\
\text { nasal irrigation }(17 \%)\end{array}$ \\
\hline \multicolumn{7}{|c|}{ Cerebrovascular disease } \\
\hline \multicolumn{7}{|l|}{ Ischaemic stroke } \\
\hline $\begin{array}{l}\text { Avula et al ; } ; \text { four } \\
\text { cases, USA }\end{array}$ & $\begin{array}{l}\text { Four patients } \\
\text { (aged } 73 \text { to } 88 \text { years) } \\
\text { with hypertension; three } \\
\text { had dyslipidaemia, } \\
\text { one diabetes and } \\
\text { neuropathy, one carotid } \\
\text { stenosis, and one chronic } \\
\text { kidney disease; } \\
\text { three presented with } \\
\text { acute new focal } \\
\text { neurological deficit } \\
\text { (facial droop, slurred } \\
\text { speech; left-sided } \\
\text { weakness; and right-arm } \\
\text { weakness and word } \\
\text { finding difficulty), and } \\
\text { one with altered mental } \\
\text { status; one had fever, } \\
\text { respiratory distress, } \\
\text { nausea, and vomiting; } \\
\text { one had fever only; one } \\
\text { had mild shortness of } \\
\text { breath with dry cough; } \\
\text { one had no respiratory } \\
\text { symptoms or fever }\end{array}$ & $\begin{array}{l}\text { All four had } \\
\text { positive RT-PCR } \\
\text { (presumed to be } \\
\text { upper respiratory } \\
\text { samples); no } \\
\text { mention of } \\
\text { (SF studies }\end{array}$ & $\begin{array}{l}\text { Negative blood and } \\
\text { urine cultures in the } \\
\text { two patients for whom } \\
\text { results were reported }\end{array}$ & $\begin{array}{l}\text { Three patients had } \\
\text { lymphopenia, one with } \\
\text { leucopenia and two with } \\
\text { leucocytosis; two had } \\
\text { elevated D-dimer and } \\
\text { inflammatory markers; } \\
\text { three had patchy changes } \\
\text { bilaterally on chest x-ray } \\
\text { or CT }\end{array}$ & $\begin{array}{l}\text { All four had evidence of } \\
\text { unifocal infarcts: three on CT, } \\
\text { one on brain MRI }\end{array}$ & $\begin{array}{l}\text { All were treated with } \\
\text { antiplatelet therapy; none } \\
\text { had thrombolysis or } \\
\text { thrombectomy; three required } \\
\text { intubation and ventilation, all } \\
\text { of whom died; fourth patient } \\
\text { discharged to rehabilitation } \\
\text { facility }\end{array}$ \\
\hline
\end{tabular}




\begin{tabular}{|c|c|c|c|c|c|c|}
\hline & Clinical presentation & $\begin{array}{l}\text { SARS-CoV-2 } \\
\text { diagnostics }\end{array}$ & $\begin{array}{l}\text { Other pathogen and } \\
\text { antibody } \\
\text { investigations }\end{array}$ & $\begin{array}{l}\text { Relevant blood tests and } \\
\text { radiology findings }\end{array}$ & $\begin{array}{l}\text { Neurological investigations } \\
\text { (CSF findings, neuroimaging, } \\
\text { neurophysiology) }\end{array}$ & $\begin{array}{l}\text { Management, progress, and } \\
\text { outcome }\end{array}$ \\
\hline \multicolumn{7}{|c|}{ (Continued from previous page) } \\
\hline $\begin{array}{l}\text { Beyrouti et al } ;^{.52} \\
\text { six cases, UK }\end{array}$ & $\begin{array}{l}\text { Six patients (aged } \\
53 \text { to } 83 \text { years; five male } \\
\text { and one female), three of } \\
\text { whom had hypertension, } \\
\text { two ischaemic heart } \\
\text { disease, two atrial } \\
\text { fibrillation, one a } \\
\text { previous stroke and high } \\
\text { body-mass index, and } \\
\text { one was a smoker with } \\
\text { heavy alcohol } \\
\text { consumption and } \\
\text { diabetes; three had } \\
\text { dysarthria, one expressive } \\
\text { dysphasia, one aphasia; } \\
\text { four had hemiparesis and } \\
\text { two had incoordination; } \\
\text { one had reduced } \\
\text { consciousness, and all } \\
\text { had respiratory } \\
\text { symptoms at a median of } \\
13 \text { days (range -2 to 24) } \\
\text { before or after } \\
\text { neurological } \\
\text { symptom onset }\end{array}$ & $\begin{array}{l}\text { All six had positive } \\
\text { RT-PCR (presumed } \\
\text { to be upper } \\
\text { respiratory } \\
\text { samples); no } \\
\text { mention of } \\
\text { CSF studies }\end{array}$ & $\begin{array}{l}\text { One had a medium } \\
\text { titre lgM anti- } \\
\text { cardiolipin antibody } \\
\text { and low titre IgG and } \\
\text { IgM a } \mathrm{a} 2 \mathrm{GP} 1 \text { antibody }\end{array}$ & $\begin{array}{l}\text { One had leucocytosis and } \\
\text { three had lymphopenia; all } \\
\text { had raised D-dimer and LDH; } \\
\text { five had raised ferritin and } \\
\text { five had raised CRP; all had } \\
\text { bilateral patchy changes on } \\
\text { chest x-ray or CT, } \\
\text { and two had pulmonary } \\
\text { emboli (one in a segmental } \\
\text { artery and one with bilateral } \\
\text { emboli in segmental and } \\
\text { subsegmental arteries) }\end{array}$ & $\begin{array}{l}\text { Initial scans (CT and brain } \\
\text { MRI) showed unifocal infarcts } \\
\text { in four patients, one of whom } \\
\text { had bilateral infarcts on a } \\
\text { follow-up brain MRl; two } \\
\text { had bilateral infarcts on } \\
\text { initial scans }\end{array}$ & $\begin{array}{l}\text { One treated with dual } \\
\text { antiplatelet and therapeutic } \\
\text { low-molecular weight heparin } \\
\text { therapy; one had external } \\
\text { ventricular drain placement } \\
\text { and therapeutic } \\
\text { low-molecular-weight } \\
\text { heparin; one had apixaban; } \\
\text { one had therapeutic } \\
\text { low-molecular weight } \\
\text { heparin; two had intravenous } \\
\text { thrombolysis; three required } \\
\text { oxygen therapy; two were } \\
\text { admitted to IC; one died } \\
\text { secondary to COVID-19 } \\
\text { pneumonia following } \\
\text { cardiorespiratory } \\
\text { deterioration }\end{array}$ \\
\hline $\begin{array}{l}\text { Li et al }\left.\right|_{;} ^{53} \\
11 \text { cases, China }\end{array}$ & $\begin{array}{l}11 \text { patients (aged } \\
57 \text { to } 91 \text { years; six female } \\
\text { and five male), nine of } \\
\text { whom had hypertension, } \\
\text { six diabetes, three } \\
\text { cardiovascular disease, } \\
\text { three were smokers, and } \\
\text { one with malignancy; } \\
\text { five had large-vessel } \\
\text { stenosis, three } \\
\text { cardioembolic, and three } \\
\text { small-vessel disease; all } \\
\text { had respiratory } \\
\text { symptoms a median of } \\
11 \text { days (range } 0 \text { to } 30 \text { ) } \\
\text { before neurological } \\
\text { symptoms onset }\end{array}$ & $\begin{array}{l}\text { All RT-PCRs were } \\
\text { positive on } \\
\text { throat swab }\end{array}$ & NR & $\begin{array}{l}\text { No specific detail given on } \\
\text { the } 11 \text { patients with } \\
\text { ischaemic stroke; all patients } \\
\text { had evidence of COVID-19 } \\
\text { pneumonia on chest CT }\end{array}$ & NR & $\begin{array}{l}\text { Nine had severe disease; } \\
\text { six were treated with } \\
\text { antiplatelets (aspirin or } \\
\text { clopidogrel); five were given } \\
\text { anticoagulant therapy } \\
\text { (clexane); four died and } \\
\text { seven survived }\end{array}$ \\
\hline $\begin{array}{l}\text { Morassi et al: }{ }^{54} \\
\text { four cases, Italy }\end{array}$ & $\begin{array}{l}\text { Four patients (aged } 64 \text { to } \\
82 \text { years), three of whom } \\
\text { had hypertension, two } \\
\text { had a previous stroke or } \\
\text { transient ischaemic } \\
\text { attack and aortic valve } \\
\text { disease, and one was a } \\
\text { smoker with a previous } \\
\text { myocardial infarction; all } \\
\text { presented with severe } \\
\text { acute respiratory illness; } \\
\text { three developed } \\
\text { neurological } \\
\text { manifestations during } \\
\text { hospitalisation } \\
\text { (two hemiparesis and } \\
\text { one inability to rouse } \\
\text { when sedation held); one } \\
\text { presented with episodes } \\
\text { of transient loss of } \\
\text { consciousness and } \\
\text { confusion }\end{array}$ & $\begin{array}{l}\text { All RT-PCRs were } \\
\text { positive on } \\
\text { nasopharyngeal } \\
\text { swab }\end{array}$ & NR & $\begin{array}{l}\text { All had raised CRP levels, } \\
\text { two each had raised D-dimer, } \\
\text { raised LDH, and abnormal } \\
\text { renal and liver function tests; } \\
\text { chest CT on all patients: } \\
\text { bilateral ground glass } \\
\text { opacities (one patient also } \\
\text { had bilateral pleural effusions } \\
\text { and a pulmonary embolism) }\end{array}$ & $\begin{array}{l}\text { One had CSF: normal } \\
\text { leukocyte count, protein, and } \\
\text { IgG index; all had multifocal } \\
\text { infarcts on brain CT or MRI; } \\
\text { the patient presenting with } \\
\text { transient loss of consciousness } \\
\text { and ensuing confusion had } \\
\text { EEG: normal background in } \\
\text { the alpha range }(8 \mathrm{~Hz}) \text {, } \\
\text { associated with recurrent } \\
\text { sharp slow waves over left } \\
\text { temporal region, which } \\
\text { occasionally were seen also on } \\
\text { the right homologous regions }\end{array}$ & $\begin{array}{l}\text { One patient treated with } \\
\text { aspirin, clopidogrel, and } \\
\text { enoxaparin; one given } \\
\text { levetiracetam; treatment not } \\
\text { reported for the remaining } \\
\text { two; two were intubated and } \\
\text { mechanically ventilated; } \\
\text { two died; of the two survivors, } \\
\text { one had coma (GCS 3/15) and } \\
\text { one was severely disabled with } \\
\text { modified Rankin score of } 4\end{array}$ \\
\hline
\end{tabular}




\begin{tabular}{|c|c|c|c|c|c|c|}
\hline & Clinical presentation & $\begin{array}{l}\text { SARS-CoV-2 } \\
\text { diagnostics }\end{array}$ & $\begin{array}{l}\text { Other pathogen and } \\
\text { antibody } \\
\text { investigations }\end{array}$ & $\begin{array}{l}\text { Relevant blood tests and } \\
\text { radiology findings }\end{array}$ & $\begin{array}{l}\text { Neurological investigations } \\
\text { (CSF findings, neuroimaging, } \\
\text { neurophysiology) }\end{array}$ & $\begin{array}{l}\text { Management, progress, and } \\
\text { outcome }\end{array}$ \\
\hline \multicolumn{7}{|c|}{ (Continued from previous page) } \\
\hline $\begin{array}{l}\text { Oxley et al, }, 55 \\
\text { five cases, USA }\end{array}$ & $\begin{array}{l}\text { Five patients (aged } \\
33 \text { to } 49 \text { years; four male } \\
\text { and one female); all had } \\
\text { hemiplegia; four had } \\
\text { reduced consciousness; } \\
\text { three had dysarthria, one } \\
\text { global dysphasia, } \\
\text { two had a sensory } \\
\text { deficit, and three had } \\
\text { systemic or respiratory } \\
\text { symptoms }\end{array}$ & $\begin{array}{l}\text { All five had positive } \\
\text { RT-PCR (presumed } \\
\text { to be upper } \\
\text { respiratory } \\
\text { samples); no } \\
\text { mention of } \\
\text { CSF studies }\end{array}$ & NR & $\begin{array}{l}\text { One had thrombocytopenia, } \\
\text { one prolonged prothrombin } \\
\text { time, one prolonged } \\
\text { activated partial } \\
\text { thromboplastin time, and } \\
\text { three each had raised } \\
\text { fibrinogen, increased } \\
\text { D-dimer, and raised ferritin; } \\
\text { CT angiography reported in } \\
\text { one patient: patchy ground } \\
\text { glass opacities in lung apices }\end{array}$ & $\begin{array}{l}\text { All had single-territory } \\
\text { infarcts on brain CT or MRI }\end{array}$ & $\begin{array}{l}\text { Four had clot retrieval, } \\
\text { one of whom had intravenous } \\
\text { thrombolysis and } \\
\text { hemicraniectomy and one had } \\
\text { stent insertion; two had } \\
\text { apixaban, two aspirin alone, } \\
\text { and one dual antiplatelets; } \\
\text { one discharged home; } \\
\text { two discharged to } \\
\text { rehabilitation facilities; } \\
\text { two remain in hospital (one in } \\
\text { ICU and one in stroke unit) }\end{array}$ \\
\hline \multicolumn{7}{|c|}{ Intracerebral haemorrhage } \\
\hline $\begin{array}{l}\text { Al Saiegh et al:;56 } \\
\text { one case, USA }\end{array}$ & $\begin{array}{l}\text { Man aged } 31 \text { years with } \\
\text { one week of malaise, } \\
\text { mild fever, cough, and } \\
\text { arthralgia had sudden } \\
\text { onset of headache and } \\
\text { loss of consciousness; } \\
\text { confused after first } \\
\text { operation }\end{array}$ & $\begin{array}{l}\text { RT-PCR was } \\
\text { positive in nasal } \\
\text { swab; CSF RT-PCR } \\
\text { was negative on } \\
\text { two samples }\end{array}$ & NR & NR & $\begin{array}{l}\text { Head CT: subarachnoid } \\
\text { haemorrhage in posterior } \\
\text { fossa; subsequent CT showed } \\
\text { hydrocephalus; cerebral } \\
\text { angiogram showed ruptured } \\
\text { dissecting right posterior- } \\
\text { inferior cerebellar artery } \\
\text { aneurysm }\end{array}$ & $\begin{array}{l}\text { External ventricular drain } \\
\text { inserted initially; then flow- } \\
\text { diverting stent placed to treat } \\
\text { ruptured aneurysm; intubated } \\
\text { for surgery but did not require } \\
\text { ongoing ventilator support; } \\
\text { postoperative confusion } \\
\text { resolved; discharged for } \\
\text { rehabilitation }\end{array}$ \\
\hline $\begin{array}{l}\text { Morassi et al:; } \\
\text { two cases, Italy }\end{array}$ & $\begin{array}{l}\text { Two men aged } 57 \text { years } \\
\text { admitted to hospital } \\
\text { with critical COVID-19; } \\
\text { at } 7 \text { and } 11 \text { days later } \\
\text { (14 and } 17 \text { days after } \\
\text { onset of cough and } \\
\text { fever, one with } \\
\text { dyspnoea), they had } \\
\text { bilaterally fixed dilated } \\
\text { pupils and coma } \\
\text { (GCS 3/15) }\end{array}$ & $\begin{array}{l}\text { Both RT-PCRs were } \\
\text { positive on } \\
\text { nasopharyngeal } \\
\text { swab }\end{array}$ & NR & $\begin{array}{l}\text { Both had raised CRP, LDH, } \\
\text { aspartate aminotransferase } \\
\text { and gamma-glutamyl } \\
\text { transpeptidase; chest CT } \\
\text { showed diffuse bilateral } \\
\text { ground glass opacities in } \\
\text { both patients }\end{array}$ & $\begin{array}{l}\text { One patient had bilateral } \\
\text { cerebellar haemorrhages on } \\
\text { brain CT with hydrocephalus; } \\
\text { the other had a large frontal } \\
\text { haemorrhage with displaced } \\
\text { ventricles and multiple } \\
\text { smaller haemorrhages }\end{array}$ & $\begin{array}{l}\text { Both patients developed } \\
\text { respiratory failure requiring } \\
\text { intubation, ventilation, and } \\
\text { admission to ICU; both } \\
\text { deteriorated neurologically, } \\
\text { and imaging confirmed } \\
\text { cerebral haemmorhage; } \\
\text { both died }\end{array}$ \\
\hline \multicolumn{7}{|c|}{ Cerebral venous sinus thrombosis } \\
\hline $\begin{array}{l}\text { Li et al, }{ }^{53} \\
\text { one case, China }\end{array}$ & $\begin{array}{l}\text { Man aged } 32 \text { years with } \\
\text { history of smoking } \\
\text { developed neurological } \\
\text { features } 14 \text { days after } \\
\text { initial presentation with } \\
\text { COVID-19 }\end{array}$ & $\begin{array}{l}\text { RT-PCR was } \\
\text { positive on } \\
\text { throat swab }\end{array}$ & NR & NR & NR & $\begin{array}{l}\text { Treated with anticoagulation; } \\
\text { survived but remains } \\
\text { in hospital }\end{array}$ \\
\hline \multicolumn{7}{|c|}{ 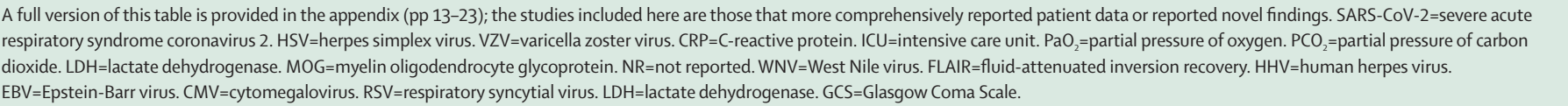 } \\
\hline
\end{tabular}

generalised slowing, two had focal abnormalities, and one patient, who presented with psychotic symptoms followed by a seizure, was found to be in non-convulsive status epilepticus. ${ }^{61}$ One patient responded quickly to high dose steroids, ${ }^{58}$ but for the other seven no specific treatment was reported beyond anticonvulsants, antiviral, and antibiotic medication.

No specific treatment exists for SARS-CoV-2 encephalitis. As for other forms of encephalitis, questions will emerge concerning the relative contributions of viral damage and host inflammatory response, and whether corticosteroids might be useful. Clinical trials seem unlikely, given the current low number of cases.

\section{Other encephalopathies}

Encephalopathy is a pathobiological process in the brain that usually develops over hours to days and can manifest as changed personality, behaviour, cognition, or consciousness (including clinical presentations of delirium or coma). ${ }^{80}$ In patients with encephalopathy and COVID-19, in whom brain inflammation has not been proven, the wide range of other causes to consider includes hypoxia, drugs, toxins, and metabolic derangements (appendix pp 2-3). ${ }^{57}$

The largest study to date, ${ }^{36}$ from Wuhan, China, retrospectively described 214 patients with COVID-19, of whom 53 (25\%) had CNS symptoms, including dizziness (36 [17\%] patients), headache (28 [13\%]), and impaired 
consciousness (16 [7\%]). 27 (51\%) of the patients with CNS symptoms had severe respiratory disease, but there was little further detail (table 2; appendix pp 1415). ${ }^{36}$ In a French series of 58 intensive care patients with COVID-19, ${ }^{35}$ $49(84 \%)$ had neurological complications, including 40 (69\%) with encephalopathy and 39 (67\%) with corticospinal tract signs. MRI in 13 patients showed leptomeningeal enhancement for eight and acute ischaemic change for two; CSF examination for seven patients showed no pleiocytosis. 15 (33\%) of 45 patients who had been discharged had a dysexecutive syndrome. Additionally, some case reports have appeared, including a woman with encephalopathy with imaging changes consistent with acute necrotising encephalopathy (figure $2 \mathrm{C}, \mathrm{D})^{37}$ and a fatal case in which viral particles were found in endothelial cells and neural tissue, although there was no indication of whether this was associated with inflammation. ${ }^{38}$

Several reports have described seizures in children with SARS-CoV-2 infection. Paroxysmal episodes consistent with seizures were described in two infants with no respiratory symptoms but SARS-CoV-2 on nasopharyngeal swab; ${ }^{34,81}$ both made a good recovery. In one series of 168 children hospitalised with COVID-19, ${ }^{82}$ seizures were described for five $(3 \%)$ children, of whom three had preexisting epilepsy and one had previous febrile seizures.

\section{Acute disseminated encephalomyelitis and myelitis}

Acute disseminated encephalomyelitis is a syndrome of multifocal demyelination, typically occurring weeks after an infection, which generally presents with focal neurological symptoms, often with encephalopathy (appendix p 7). ${ }^{83}$ Two case reports ${ }^{40,41}$ describe middle-aged women with acute disseminated encephalomyelitis and SARS-CoV-2 detected on respiratory swabs (table 2; appendix p 16). One developed dysphagia, dysarthria, and encephalopathy 9 days after the onset of headache and myalgia (figure 1). ${ }^{41}$ The other presented with seizures and reduced consciousness, and required intubation for respiratory failure. ${ }^{40}$ Both patients had normal CSF and high signal intensities on MRI, typical of acute disseminated encephalomyelitis. They both improved after treatment, one with intravenous immunoglobulin and one with steroids. To date, a single report exists of myelitis (inflammation of the spinal cord; appendix $\mathrm{p}$ 8) associated with COVID-19. A man aged 66 years in Wuhan, China, developed fever, fatigue, and then acute flaccid paraparesis with incontinence. Examination showed hyporeflexia and a sensory level at T10. He was treated with dexamethasone and intravenous immunoglobulin, and was discharged for rehabilitation. ${ }^{42}$

Acute disseminated encephalomyelitis and myelitis, usually considered post-infectious diseases, are treated typically with corticosteroids or other immunotherapies. In these para-infectious cases, with SARS-CoV-2 detectable at presentation, clinicians might need to be more cautious, especially if the virus is detected in the CSF, because such treatment might diminish the patient's immune response to the virus.

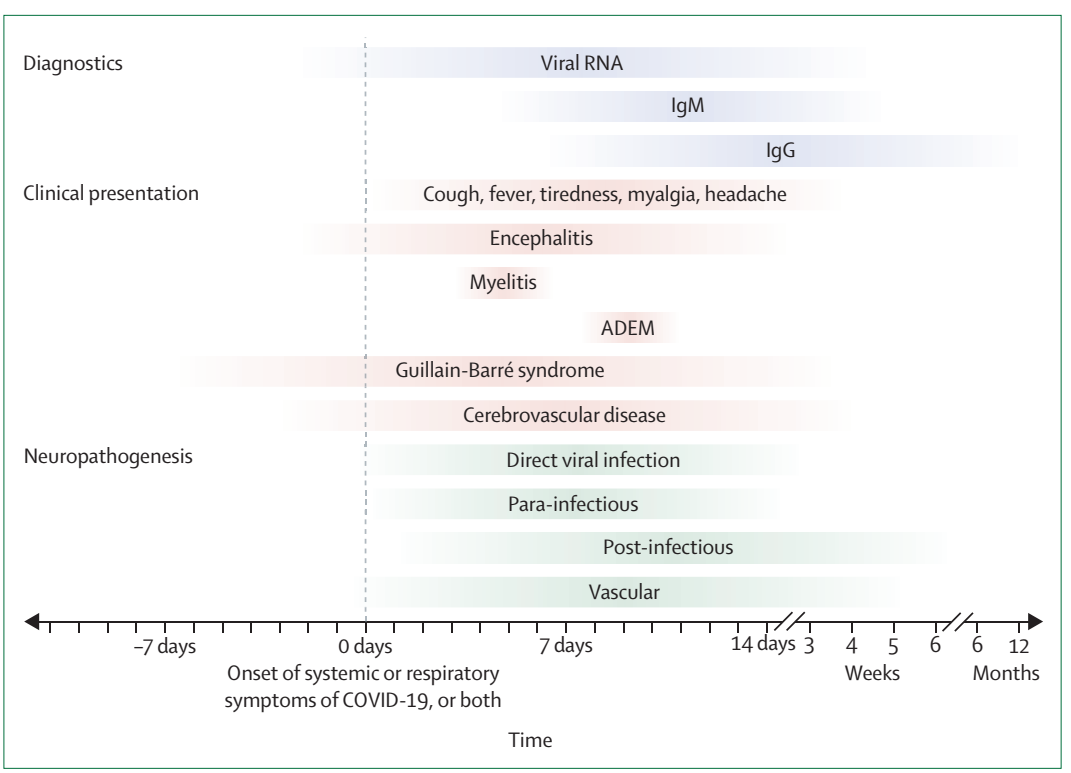

Figure 1: Approximate timeline for positive diagnostic tests, clinical presentation, and pathogenesis in COVID-19-associated neurological disease

Approximate values are based on currently published data. Bars are faded to indicate uncertainty about specific ranges. Blue bars represent the period in which SARS-CoV-2 viral RNA and anti-SARS-CoV-2 IgM or IgG antibodies are detectable on either RT-PCR or antibody testing. ${ }^{62-67}$ Red bars represent the time of clinical presentation, including the duration of systemic or respiratory symptoms of COVID-19 and the time interval between onset of COVID-19 symptoms and symptoms of encephalitis, ${ }^{31-33.58-61}$ myelitis, ${ }^{42}$ acute disseminated encephalomyelitis, ${ }^{40,41}$ Guillain-Barré syndrome, ${ }^{43-48,68-75}$ or cerebrovascular disease..$^{52-54,76-79} \mathrm{~A}$ small number of patients who presented with neurological disease and never had respiratory features of COVID-19 are not represented in the figure. Green bars represent pathological mechanisms that might result in neurological disease in COVID-19, as in other viruses (appendix $\mathrm{p} 4$ ). The dynamics of anti-SARS-CoV-2 IgG antibody production are not known beyond a few weeks, although by analogy with other viruses, it might be expected to persist for months to years. ADEM=acute disseminated encephalomyelitis. SARS-CoV-2=severe acute respiratory syndrome coronoavirus 2.

\section{Peripheral nervous system and muscle disease}

Guillain-Barré syndrome is an acute polyradiculopathy characterised by rapidly progressive, symmetrical limb weakness, areflexia on examination, sensory symptoms, and, in some patients, facial weakness, although several variants exist (appendix p 9). To date, 19 patients (six female) with Guillain-Barré syndrome or its variants and COVID-19 have been reported, with a median age of 63 years (range 23 to 77; table 2; appendix pp 16-18). Given the number of SARS-CoV-2 infections worldwide, the incidence is not particularly higher than what might be expected. ${ }^{84}$ Neurological symptoms started at a median of 7 days (range -7 to 24 ) after respiratory or systemic features (figure 1), although two patients developed febrile illness 7 days after the onset of Guillain-Barré syndrome; ${ }^{45,68}$ on hospital admission, one had a positive swab for SARSCoV-2 and the other had lymphocytopenia and thrombocytopenia, which are characteristic for SARS-CoV-2 infection. Three patients had diarrhoea before the onset of neurological disease.

11 patients had Guillain-Barré syndrome with weakness of all four limbs with or without sensory loss, ${ }^{43-45,69-74}$ three had a paraparetic variant with leg weakness only, ${ }^{44,68,75}$ and one had lower limb paraesthesia. ${ }^{44}$ Four of these patients had facial nerve involvement, five had dysphagia, 

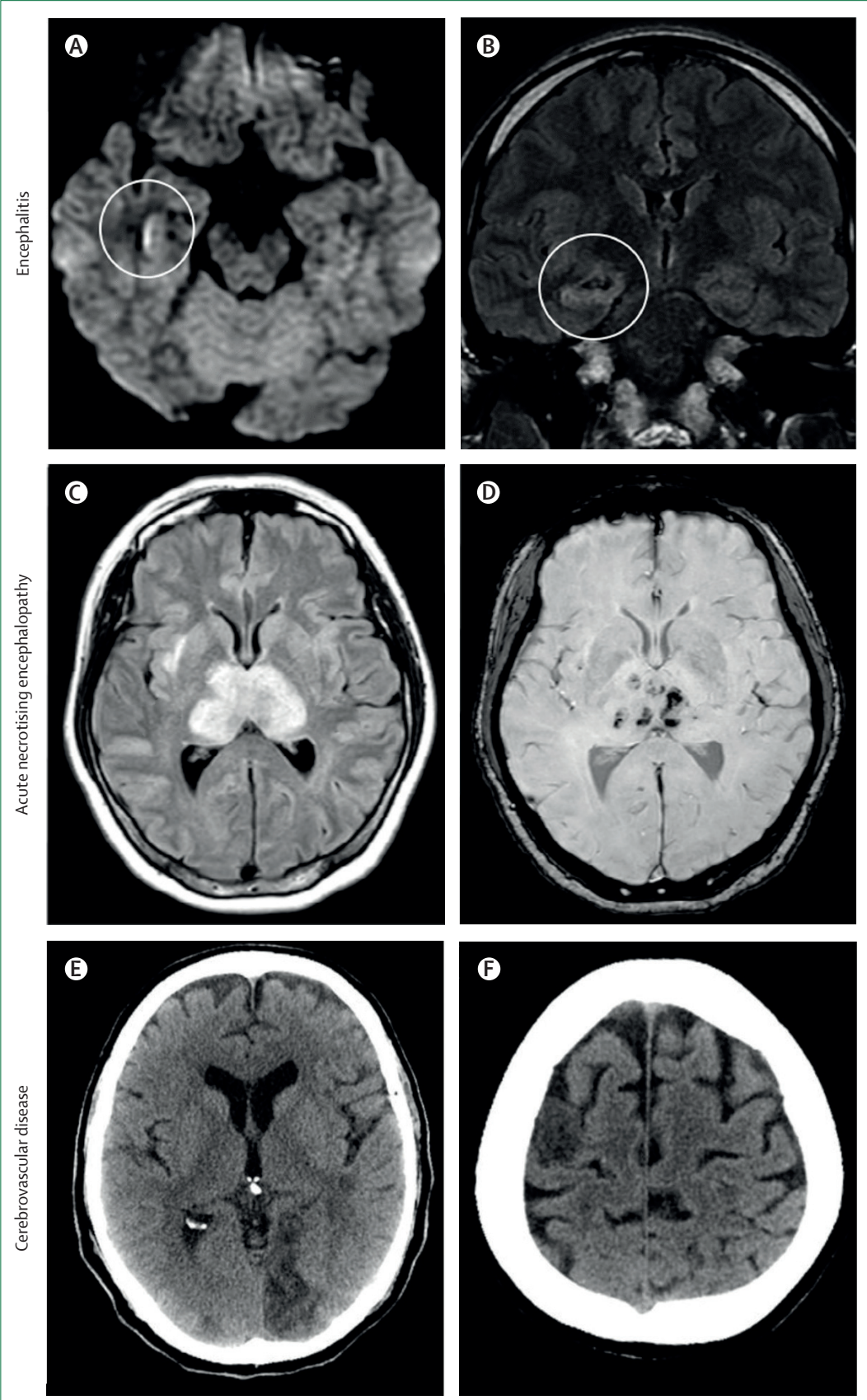

Figure 2: Brain imaging in patients with neurological disease associated with COVID-19 (A) Hyperintensity along the wall of inferior horn of right lateral ventricle on diffusion-weighted imaging, indicating ventriculitis. (B) hyperintense signal changes in the right mesial temporal lobe and hippocampus with slight hippocampal atrophy on FLAIR MRI, consistent with encephalitis, in a patient with COVID-19. ${ }^{31}$ (C) Hyperintensity within the bilateral medial temporal lobes and thalami on T2/FLAIR MRI. (D) Evidence of haemorrhage, indicated by hypointense signal on susceptibility-weighted images, consistent with acute necrotising encephalopathy in a patient with confirmed COVID-19. ${ }^{37}$ (E) CT showing ischaemic lesions involving the left occipital lobe. (F) Right frontal precentral gyrus of the brain in a man aged 64 years who deteriorated neurologically after admission to hospital with COVID-19 and was diagnosed with acute stroke. ${ }^{54}$ FLAIR=fluid-attenuated inversion recovery. Panels $A$ and $B$ reproduced from Moriguchi et a ${ }^{31}$ with permission from Elsevier under a creative commons CC BY-NC-ND license; panels C and D reproduced from Poyiadji et a ${ }^{37}$ with permission from The Radiological Society of North America; and panels E and F reproduced from Morassi et al ${ }^{54}$ with permission from Springer Nature. and eight developed respiratory failure. Three had autonomic complications, one with hypertension and two with sphincter dysfunction. Electrophysiological studies were done in 12 patients and were consistent with demyelinating disease in eight and axonal disease in four patients.

Two patients had the Miller Fisher variant of GuillainBarré syndrome, with ophthalmoplegia, ataxia, and areflexia; ${ }^{46,47}$ one also had loss of smell and taste, and was positive for anti-GD1b-IgG. One patient had bilateral and one patient unilateral abducens palsy, ${ }^{46,47}$ and another had an acute vestibular syndrome with horizontal nystagmus and oscillopsia. ${ }^{48}$

For 16 patients, SARS-CoV-2 was detected in a respiratory swab, and for two, the sample was not specified; one patient was also positive for rhinovirus. One patient was diagnosed by a blood antibody test. Lumbar puncture was done in 13 patients and showed albuminocytological dissociation in 11. SARS-CoV-2 was not detected in any CSF samples. Testing for other pathogens commonly associated with Guillain-Barré syndrome was reported for only four patients. ${ }^{43,4,73,75} 15$ patients were treated with intravenous immunoglobulin, and eight (all with classical Guillain-Barré syndrome) were admitted to intensive care for ventilatory support, two of whom died. ${ }^{70,71} 12 \mathrm{improved}$, and five had ongoing disability at discharge.

Muscle injury associated with raised creatine kinase affected $23(11 \%)$ of 214 patients in the Wuhan series. ${ }^{57}$ Rhabdomyolysis due to COVID-19 has also been reported..$^{85,86}$

Loss of smell (anosmia) and taste (ageusia) have emerged as common symptoms of COVID-19, either with other features or in isolation, suggesting that they might be useful diagnostic markers (appendix p 19). ${ }^{87}$ A study of 259 patients, ${ }^{88}$ including 68 who were positive for SARS-CoV-2, found that abnormal smell and taste were both strongly associated with COVID-19. In a European study, ${ }^{50}$ olfactory dysfunction was reported for 357 (86\%) of 417 COVID-19 patients; 342 (82\%) reported gustatory disorders. These symptoms were reported more frequently for COVID-19 patients than for a historical cohort of influenza patients. ${ }^{89}$ Subclinical deficits in smell, taste, or both have also been detected. ${ }^{00,91}$ Although these symptoms can occur in any respiratory infection because of coryza, the fact they occur in isolation of other symptoms suggest that there is involvement of the olfactory nerve.

\section{Cerebrovascular manifestations}

As COVID-19 has spread around the world, evidence has grown for an association with cerebrovascular disease, as well as with other forms of vascular disease. Cerebrovascular manifestations were reported for 13 (6\%) of 221 COVID-19 patients in an early retrospective case series from Wuhan: ${ }^{33} 11(5 \%)$ patients developed ischaemic stroke, one $(<1 \%)$ had intracerebral haemorrhage, and one $(<1 \%)$ had cerebral venous sinus thrombosis. In Milan, Italy, nine (2\%) of 388 retrospectively identified hospital patients with laboratory-confirmed COVID-19 had a stroke. ${ }^{92}$ Another 
centre in Italy reported that 43 (77\%) of 56 SARS-CoV-2positive patients admitted to one neurology unit had cerebrovascular disease; 35 had ischaemic stroke and three haemorrhagic stroke, and five had transient ischaemic attacks. ${ }^{93}$ In the Netherlands, three (2\%) of 184 patients in intensive care with COVID-19 had ischaemic strokes. ${ }^{94}$ In total, 88 patients with ischaemic stroke and eight with haemorrhagic stroke $e^{53,54,5,7,93}$ have been reported, 18 (19\%) of whom died (table 2; appendix pp 20-23).

Most patients were older than 60 years, and many had known risk factors for cerebrovascular disease, especially hypertension, diabetes, hyperlipidaemia, and vascular disease. ${ }^{51-54,7,78}$ Younger stroke patients have also been reported. ${ }^{52,55,56,92,95}$ In one hospital in New York, NY, USA, five patients younger than 50 years with stroke and SARS$\mathrm{CoV} 2$ were admitted in just 2 weeks, whereas the average number of admissions for young patients with stroke per 2 weeks in the preceding year was $0 \cdot 73 .{ }^{55}$ Two patients had no other symptoms of COVID-19. All had large vessel ischaemic strokes.

Cerebrovascular symptoms began at a median of 10 days (range 0-33) after the onset of respiratory illness (figure 1), although in one patient the stroke preceded respiratory features ${ }^{36}$ and five had only cerebrovascular symptoms. . $^{51,55,56,95}$

In two patients, ischaemic stroke has been associated with thrombus in the aorta, ${ }^{95,96}$ and indeed multiple infarcts have been reported in these and other patients (figure 2E, F), ${ }^{52,77,79}$ sometimes associated with arterial thrombosis and limb ischaemia. ${ }^{779}$ Concurrent deep vein thrombosis and pulmonary embolism have been found in other stroke patients. ${ }^{52,95}$ Arterial and venous imaging is clearly essential for COVID-19 patients with acute cerebrovascular events. Small asymptomatic infarcts identified on MRI only have also been described..$^{35}$ Blood D-dimer concentration was raised in many patients with COVID-19, consistent with a pro-inflammatory, coagulopathic state in the setting of critical illness. ${ }^{51-55,77,92,95,96}$ Positive lupus anticoagulant, anticardiolipin, and anti- $\beta 2$ glycoprotein-1 antibodies have also been reported in COVID-19-associated stroke, ${ }^{52 \pi}$ although these can be raised in other critical illnesses, including infections.

Immediate anticoagulation with low-molecular-weight heparin has been recommended for patients with COVID-19, to reduce the risk of thrombotic disease. ${ }^{97}$ This approach might also reduce COVID-19-associated ischaemic stroke, but it must be balanced against the risk of intracranial haemorrhage, including haemorrhagic transformation of an acute infarct. Several randomised trials are looking at the role of anticoagulation in patients with COVID-19 (NCT04362085, NCT04345848, NCT04406389), including the effect on stroke incidence.

\section{Disease mechanisms \\ Infection and inflammation of the central and peripheral nervous systems}

As with other neurotropic viruses, key questions for SARS-CoV-2 infection concern the routes of entry into the nervous system and the relative contribution of viral infection versus host response to the subsequent damage (appendix p 12).

Viral entry to the brain through the olfactory bulb- the only part of the CNS not protected by dura-is one plausible route for SARS-CoV-2, especially given the anosmia in COVID-19. This entry route is thought to be used by the herpes simplex virus, the most common cause of sporadic viral encephalitis. ${ }^{98}$ In mouse models, following intranasal injection, human coronavirus OC43 invades the CNS by the olfactory route..$^{99}$ Alternative entry routes include carriage across the blood-brain barrier, following viraemia, or through infected leukocytes. ${ }^{3}$ The angiotensin converting enzyme 2 receptor, to which SARS-CoV-2 binds for entry into cells,${ }^{100}$ is found in brain vascular endothelium and smooth muscle. ${ }^{101}$ SARS-CoV-2 replicates in neuronal cells in vitro. ${ }^{102}$

Damage within the CNS or PNS might be caused directly by the virus or by the body's innate and adaptive immune responses to infection. Data so far do not suggest that SARS-CoV-2 or related coronaviruses are highly neurovirulent, unlike herpes simplex virus, some enteroviruses, and some arthropod-borne viruses, which can cause rampant destruction of neurons. ${ }^{98}$

Autopsy material from a patient who developed encephalopathy weeks after presenting with SARS showed oedema, neuronal necrosis, and broad gliocyte hyperplasia. ${ }^{8}$ Immunohistochemical staining showed that SARS$\mathrm{CoV}$ in the brain was associated with elevated expression of the cytokine, monokine induced by gamma interferon (known as MIG or CXCL9), and with infiltration of monocytes and macrophages plus $\mathrm{T}$ cells. These findings are consistent with viral CNS entry triggering the infiltration of immune cells and the release of cytokines and chemokines, which contribute to tissue damage.

Little work has been done on disease mechanisms for coronavirus PNS disease. By comparison with other viruses, it would not be surprising to see immunemediated disease, such as Guillain-Barré syndrome, and direct anterior horn cell viral damage, which causes acute flaccid myelitis, might also be expected. ${ }^{103}$

\section{Cerebrovascular disease}

Early indicators suggest that cerebrovascular disease in COVID-19 might be due to a coagulopathy. SARS-CoV-2 can cause damage to endothelial cells, activating inflammatory and thrombotic pathways. ${ }^{104}$ Endothelial cell infection or monocyte activation, upregulation of tissue factors, and the release of microparticles, which activate the thrombotic pathway and cause microangiopathy, might occur for SARS-CoV-2 as for other viruses..$^{105,106}$ Monocyte activation is postulated to constitute part of the secondary haemophagocytic lymphohistiocytosis described in severe COVID-19. ${ }^{107}$ Thrombocytopenia with elevated D-dimer and C-reactive protein in severe COVID-19 and stroke are consistent with a virus-associated microangiopathic process. $^{53}$ Endothelial dysfunction can potentially lead to 
microvascular and macrovascular complications in the brain, as described systemically. ${ }^{94}$

Acute ischaemic stroke might also occur through the early inflammatory process, following acute infection, destabilising a carotid plaque or triggering atrial fibrillation. ${ }^{108} \mathrm{~A}$ vasculitis process similar to that for varicella zoster virus, in which viral replication in the cerebral arterial wall triggers local inflammation, ${ }^{109}$ is also plausible; endothelial infection by SARS-CoV-2 with inflammation and apoptosis of endothelial cells has been shown in kidney, heart, bowel, and lung at autopsy, ${ }^{104}$ but cerebral vessels have not yet been investigated.

\section{Investigating for neurological disease}

As SARS-CoV-2 continues to spread and patients with neurological symptoms are seen increasingly, it is essential that the desire to publish quickly is balanced with the need for careful clinical, diagnostic, and epidemiological studies. Clinicians must adopt a methodical approach to investigating patients with possible COVID-19-associated neurological disease, and must systematically consider the evidence for viral infection and the presenting clinical diagnosis, using definitions that distinguish confirmed, probable, and possible cases (panel; appendix pp 5-12).

Given that SARS-CoV-2 causes a large number of asymptomatic or mildly symptomatic infections, it is crucial to remember that patients with neurological disease from other causes might be infected coincidentally with the virus, including in hospital through nosocomial transmission. A full investigation, which is absent in many reports to date, is needed to rule out other established causes of brain infections before attributing disease to COVID-19. ${ }^{57,110}$ Distinguishing between nasopharyngeal SARS-CoV-2 infection and nervous system infection is also key.

For patients with altered consciousness or agitation, all causes of encephalopathy must be considered, including hypoxia, drugs, toxins, and metabolic derangement; encephalitis should be diagnosed only if clinical evidence exists of brain inflammation, such as a CSF pleiocytosis, imaging changes, focal seizures, or histological changes (appendix p 6). ${ }^{57}$ Even if virus is detected in the CSF, encephalitis should not be diagnosed unless evidence exists of brain inflammation. For patients with possible peripheral nerve disease, clinicians should aim to do CSF examination, looking for evidence of albuminocytological dissociation (an elevated CSF protein level with a normal CSF cell count), nerve conduction studies, and electromyography during recovery, even if they cannot be done acutely.

In patients with neuropathy, cerebrovascular disease, or acute disseminated encephalomyelitis, in whom the damage is probably caused by the host's response to viral infection, establishing causality is even more challenging, especially if patients present after the virus has been cleared from the nasopharynx. Clinical case definitions for COVID-19 that are based on the history and typical findings for chest imaging and blood investigations will be useful (panel). For patients with stroke, clinicians should consider cerebral angiography, intracranial vessel wall imaging, and, if necessary, brain biopsy, looking for vasculitis. The apparently high incidence of cerebrovascular disease in patients with COVID-19, with predominantly large vessel disease and markers of a highly prothrombotic state, suggest a causal relationship. However, the high prevalence of the virus during the pandemic, and the fact that most stroke patients have other risk factors, mean that it is hard to be sure about causation. The link with SARS-CoV-2 will ultimately need to be proven by careful case-control studies.

In investigating patients with limb weakness and sensory change, it is crucial to distinguish between disease of the peripheral nerves (eg, Guillain-Barré syndrome) and inflammation of the spinal cord, which can present with flaccid paralysis if the anterior horn cells are involved. ${ }^{103}$ CSF examination, neurophysiological studies, and spinal imaging are essential.

For patients on intensive care, determining whether neuropathy, myopathy, encephalopathy, or cerebrovascular disease are non-specific manifestations of critical illness or are specific to the virus itself might be particularly challenging; no reliable markers exist for neurological disease caused by critical illness, although it tends to occur after several weeks. ${ }^{10} \mathrm{Up}$ to $70 \%$ of patients with sepsis might develop encephalopathy or polyneuropathy. ${ }^{111}$ In the Wuhan series, neurological complications were more common in those with severe disease, suggesting that some of the neurological manifestations were related to critical illness. ${ }^{36,112}$

\section{Conclusion and future directions}

Given existing knowledge of other coronaviruses and respiratory viruses, the wide range of CNS and PNS associations with COVID-19 is not surprising, and this is the focus of most current reports. However, neurological disease is also likely to be seen increasingly in patients who are SARS-CoV-2-positive but with few or no typical features of COVID-19, based on knowledge of other epidemic viral infections and cases reported so far. ${ }^{28}$ Casecontrol studies will be needed to help establish whether SARS-CoV-2 is causal or coincidental in such patients. Hypercoagulable states and cerebrovascular disease, which have been seen rarely for some acute viral infections, are an important neurological complication of COVID-19.

Overall, the proportion of patients with neurological manifestations is small compared with that with respiratory disease. However, the continuing pandemic, and the expectation that $50-80 \%$ of the world's population might be infected before herd immunity develops, suggest that the overall number of patients with neurological disease could become large. Neurological complications, particularly encephalitis and stroke, can cause lifelong disability, with associated long-term care needs and 


\section{Search strategy and selection criteria}

We searched PubMed and Scopus for articles on COVID-19 from database inception to May 19, 2020, without language restrictions, using the terms "COVID-19", "novel coronavirus", "SARS-CoV-2", or "coronavirus" in combination with "neurological", "nervous system", "encephalitis", "encephalopathy", "seizure", "ataxia", "myelopathy", "Guillain-Barré syndrome", "myopathy", "peripheral neuropathy", "neuritis", "cerebrovascular", "stroke", "neuromuscular", or "brain", modified as per requirements for the search tool of each database. We reviewed the references of relevant studies for additional articles and consulted experts in the field to ensure that we did not miss important preprints and unpublished studies. Articles were included on the basis of relevance and originality with regards to the topics covered in this Rapid Review.

potentially large health, social, and economic costs. Health-care planners and policy makers need to be aware of the growing burden.

Careful clinical, diagnostic, and epidemiological studies are needed to help define the neurological disease manifestations and burden. This work will involve the collaboration of a range of clinical and research expertise, and harmonised approaches across regions; smaller case series and registries should be combined into metaanalyses such as that of the COVID-19 Neuro Network run through Brain Infections Global, which is also providing standardised case record forms and case definitions.

\section{Contributors}

MAE, BDM, JS, and TS devised the idea for this Rapid Review. MAE, LB, $\mathrm{BS}, \mathrm{SL}, \mathrm{BDM}, \mathrm{RK}, \mathrm{SD}, \mathrm{JS}$, and TS contributed to the literature search. MAE, LB, BS, SL, BDM, and TS designed and drafted the figures. MAE, LB, BS, SL, BDM, RK, SD, JS, and TS prepared the initial manuscript draft. All authors contributed to, reviewed, and approved the final draft of the paper.

\section{Declaration of interests}

TS was an adviser to the GlaxoSmithKline Ebola Vaccine programme, chaired a Siemens Diagnostics clinical advisory board, and advises the WHO Brain Health Unit Forum on Neurology and COVID-19; TS has also previously filed a patent for a test for bacterial meningitis based on a blood test (GB 1606537.7, April 14, 2016). All other authors declare no competing interests.

\section{Acknowledgments}

MAE, SL, and TS are supported by the European Union's Horizon 2020 research and innovation programme, ZikaPLAN (Preparedness Latin America Network; grant 734584). Additionally, MAE is supported by the Association of British Neurologists though a Clinical Research Training Fellowship. BS, SL, BDM, and TS are supported by the National Institute for Health Research (NIHR) Global Health Research Group on Brain Infections (17/63/110) and the NIHR Health Protection Research Unit in Emerging and Zoonotic Infections at University of Liverpool in partnership with Public Health England, in collaboration with Liverpool School of Tropical Medicine and the University of Oxford (NIHR200907). The views expressed are those of the authors and not necessarily those of the National Health Service, the NIHR, the Department of Health, or Public Health England. BDM has received funding from the Medical Research Council, Wellcome Trust, and Academy of Medical Sciences. We are also grateful for the support of Liverpool Health Partners and the Centre of Excellence in Infectious Disease Research, Liverpool.
References

1 Dong E, Du H, Gardner L. An interactive web-based dashboard to track COVID-19 in real time. Lancet Infect Dis 2020; 20: 533-34.

2 Taubenberger JK, Morens DM. 1918 influenza: the mother of al pandemics. Emerg Infect Dis 2006; 12: 15-22.

3 Desforges M, Le Coupanec A, Dubeau P, et al. Human coronaviruses and other respiratory viruses: underestimated opportunistic pathogens of the central nervous system? Viruses 2019; 12: 12.

4 Ksiazek TG, Erdman D, Goldsmith CS, et al. A novel coronavirus associated with severe acute respiratory syndrome. $N$ Engl J Med 2003; 348: 1953-66.

5 Saad M, Omrani AS, Baig K, et al. Clinical aspects and outcomes of 70 patients with Middle East respiratory syndrome coronavirus infection: a single-center experience in Saudi Arabia. Int J Infect Dis 2014; 29: 301-06.

6 Hung EWC, Chim SSC, Chan PKS, et al. Detection of SARS coronavirus RNA in the cerebrospinal fluid of a patient with severe acute respiratory syndrome. Clin Chem 2003: 49: 2108-09.

7 Lau KK, Yu WC, Chu CM, Lau ST, Sheng B, Yuen KY. Possible central nervous system infection by SARS coronavirus. Emerg Infect Dis 2004; 10: 342-44.

$8 \mathrm{Xu} \mathrm{J}$, Zhong S, Liu J, et al. Detection of severe acute respiratory syndrome coronavirus in the brain: potential role of the chemokine mig in pathogenesis. Clin Infect Dis 2005; 41: 1089-96.

9 Tsai LK, Hsieh ST, Chao CC, et al. Neuromuscular disorders in severe acute respiratory syndrome. Arch Neurol 2004; 61: 1669-73.

10 Vanhorebeek I, Latronico N, Van den Berghe G. ICU-acquired weakness. Intensive Care Med 2020; 46: 637-53.

11 Algahtani H, Subahi A, Shirah B. Neurological complications of Middle East respiratory syndrome coronavirus: a report of two cases and review of the literature. Case Rep Neurol Med 2016; 2016: 3502683.

12 Arabi YM, Harthi A, Hussein J, et al. Severe neurologic syndrome associated with Middle East respiratory syndrome corona virus (MERS-CoV). Infection 2015; 43: 495-501.

13 Kim JE, Heo JH, Kim HO, et al. Neurological complications during treatment of Middle East respiratory syndrome. J Clin Neurol 2017; 13: $227-33$

14 Morfopoulou S, Brown JR, Davies EG, et al. Human coronavirus OC43 associated with fatal encephalitis. N Engl J Med 2016; 375: 497-98.

15 Yeh EA, Collins A, Cohen ME, Duffner PK, Faden H. Detection of coronavirus in the central nervous system of a child with acute disseminated encephalomyelitis. Pediatrics 2004; 113: e73-76.

$16 \mathrm{Li} \mathrm{Y,} \mathrm{Li} \mathrm{H,} \mathrm{Fan} \mathrm{R,} \mathrm{et} \mathrm{al.} \mathrm{Coronavirus} \mathrm{infections} \mathrm{in} \mathrm{the} \mathrm{central}$ nervous system and respiratory tract show distinct features in hospitalized children. Intervirology 2016; 59: 163-69.

17 Goenka A, Michael BD, Ledger E, et al. Neurological manifestation of influenza infection in children and adults: results of a National British Surveillance Study. Clin Infect Dis 2014; 58: 775-84.

18 Studahl M. Influenza virus and CNS manifestations. J Clin Virol 2003; 28: 225-32

19 Gu Y, Shimada T, Yasui Y, Tada Y, Kaku M, Okabe N. National surveillance of influenza-associated encephalopathy in Japan over six years, before and during the 2009-2010 influenza pandemic. PLoS One 2013; 8: e54786.

20 Kwon S, Kim S, Cho M, Seo H. Cho M Hyun, Seo H. Neurologic complications and outcomes of pandemic (H1N1) 2009 in Korean children. J Korean Med Sci 2012; 27: 402.

21 Khandaker G, Zurynski Y, Buttery J, et al. Neurologic complications of influenza A(H1N1)pdm09: surveillance in 6 pediatric hospitals. Neurology 2012; 79: 1474-81.

22 Glaser CA, Winter K, DuBray K, et al. A population-based study of neurologic manifestations of severe influenza A(H1N1)pdm09 in California. Clin Infect Dis 2012; 55: 514-20.

23 Foley PB. Encephalitis lethargica and influenza. I. The role of the influenza virus in the influenza pandemic of 1918/1919. J Neural Transm (Vienna) 2009; 116: 143-50.

24 Tobi H, van den Berg PB, de Jong-van den Berg LTW. Small proportions: what to report for confidence intervals? Pharmacoepidemiol Drug Saf 2005; 14: 239-47.
For more on the COVID-19 Neuro Network of Brain Infections Global see https://braininfectionsglobal. tghn.org/covid-neuro-network/ 
25 Varatharaj A, Thomas N, Ellul M, et al. UK-wide surveillance of neurological and neuropsychiatric complications of COVID-19: the first 153 patients. SSRN 2020; published online May 22 https://papers.ssrn.com/sol3/papers.cfm?abstract_id=3601761 (preprint).

26 WHO. Coronavirus disease 2019 (COVID-19): situation report, 61. Geneva: World Health Organization, 2020

27 WHO. Laboratory testing for coronavirus disease 2019 (2019-nCoV) in suspected human cases. Geneva: World Health Organization, 2020.

28 Solomon T, Dung NM, Vaughn DW, et al. Neurological manifestations of dengue infection. Lancet 2000; 355: 1053-59.

29 Granerod J, Cunningham R, Zuckerman M, et al. Causality in acute encephalitis: defining aetiologies. Epidemiol Infect 2010; 138: 783-800.

30 Mehta R, Soares CN, Medialdea-Carrera R, et al. The spectrum of neurological disease associated with Zika and chikungunya viruses in adults in Rio de Janeiro, Brazil: a case series. PLoS Negl Trop Dis 2018; 12: e0006212.

31 Moriguchi T, Harii N, Goto J, et al. A first case of meningitis/ encephalitis associated with SARS-coronavirus-2. Int J Infect Dis 2020; 94: 55-58.

32 Sohal S, Mossammat M. COVID-19 presenting with seizures. IDCases 2020; 20: e00782.

33 Wong PF, Craik S, Newman P, et al. Lessons of the month 1: a case of rhombencephalitis as a rare complication of acute COVID-19 infection. Clin Med (Lond) 2020; published online May 5. https://doi.org.10.7861/clinmed.2020-0182.

34 Dugue R, Cay-Martínez KC, Thakur KT, et al. Neurologic manifestations in an infant with COVID-19. Neurology 2020; published online April 23. https://doi.org.10.1212/ WNL.0000000000009653.

35 Helms J, Kremer S, Merdji H, et al. Neurologic features in severe SARS-CoV-2 infection. N Engl J Med 2020; 382: 2268-70.

36 Mao L, Jin H, Wang M, et al. Neurologic manifestations of hospitalized patients with coronavirus disease 2019 in Wuhan, China. JAMA Neurol 2020; published online April 10. https://doi.org.10.1001/jamaneurol.2020.1127.

37 Poyiadji N, Shahin G, Noujaim D, Stone M, Patel S, Griffith B. COVID-19-associated acute hemorrhagic necrotizing encephalopathy: CT and MRI features. Radiology 2020; published online March 31. https://doi.org.10.1148/radiol.2020201187.

38 Paniz-Mondolfi A, Bryce C, Grimes Z, et al. Central nervous system involvement by severe acute respiratory syndrome coronavirus-2 (SARS-CoV-2). J Med Virol 2020; 92: 699-702.

39 Zhou L, Zhang M, Wang J, Gao J. Sars-Cov-2: underestimated damage to nervous system. Travel Med Infect Dis 2020; published online March 24. DOI:10.1016/j.tmaid.2020.101642.

40 Zanin L, Saraceno G, Panciani PP, et al. SARS-CoV-2 can induce brain and spine demyelinating lesions. Acta Neurochir (Wien) 2020 published online May 4. https://doi.org.10.1007/s00701-020-04374-x.

41 Zhang T, Rodricks MB, Hirsh E. COVID-19-associated acute disseminated encephalomyelitis: a case report. medRxiv 2020 https://doi.org.2020.04.16.20068148 (preprint).

42 Zhao K, Huang J, Dai D, Feng Y, Liu L, Nie S. Acute myelitis after SARS-CoV-2 infection: a case report. medRxiv 2020. https://doi.org.2020.03.16.20035105 (preprint).

43 Camdessanche J-P, Morel J, Pozzetto B, Paul S, Tholance Y, Botelho-Nevers E. COVID-19 may induce Guillain-Barré syndrome. Rev Neurol (Paris) 2020; 176: 516-18.

44 Toscano G, Palmerini F, Ravaglia S, et al. Guillain-Barré syndrome associated with SARS-CoV-2. N Engl J Med 2020; published online April 17. DOI:10.1056/NEJMc2009191.

45 Zhao H, Shen D, Zhou H, Liu J, Chen S. Guillain-Barre syndrome associated with SARS-CoV-2 infection: causality or coincidence? Lancet Neurol 2020; 19: 383-84.

46 Gutiérrez-Ortiz C, Méndez A, Rodrigo-Rey S, et al. Miller Fisher Syndrome and polyneuritis cranialis in COVID-19. Neurology 2020; published online April 17. https://doi.org.10.1212/ WNL.0000000000009619.

47 Dinkin M, Gao V, Kahan J, et al. COVID-19 presenting with ophthalmoparesis from cranial nerve palsy. Neurology 2020; published online May 1. https://doi.org.10.1212/ WNL.0000000000009700.
48 Escalada Pellitero S, Garriga Ferrer-Bergua L. Report of a patient with neurological symptoms as the sole manifestation of SARS-CoV-2 infection. Neurologia 2020; 35: 271-71.

49 Jin M, Tong Q. Rhabdomyolysis as potential late complication associated with COVID-19. Emerg Infect Dis 2020; published online March 20. https://doi.org.10.3201/eid2607.200445.

50 Lechien JR, Chiesa-Estomba CM, De Siati DR, et al. Olfactory and gustatory dysfunctions as a clinical presentation of mild-to-moderate forms of the coronavirus disease (COVID-19): a multicenter European study. Eur Arch Otorhinolaryngol 2020; published online April 6. https://doi.org.10.1007/s00405-02005965-1.

51 Avula A, Nalleballe K, Narula N, et al. COVID-19 presenting as stroke. Brain Behav Immun 2020; published online April 28. https://doi.org.10.1016/j.bbi.2020.04.077.

52 Beyrouti R, Adams ME, Benjamin L, et al. Characteristics of ischaemic stroke associated with COVID-19.

J Neurol Neurosurg Psychiatry 2020; published online April 30. DOI:jnnp-2020-323586.

53 Li Y, Wang M, Zhou Y, et al. Acute cerebrovascular disease following COVID-19: a single center, retrospective, observational study. 2020. https://media.tghn.org/medialibrary/2020/06/Li_2020_Preprint_ Acute_cerebrovascular_disease_COVID19.pdf (preprint).

54 Morassi M, Bagatto D, Cobelli M, et al. Stroke in patients with SARS-CoV-2 infection: case series. J Neurol 2020; published online May 20. https://doi.org.10.1007/s00415-020-09885-2.

55 Oxley TJ, Mocco J, Majidi S, et al. Large-vessel stroke as a presenting feature of Covid-19 in the young. N Engl J Med 2020 382: e60.

56 Al Saiegh F, Ghosh R, Leibold A, et al. Status of SARS-CoV-2 in cerebrospinal fluid of patients with COVID-19 and stroke. J Neurol Neurosurg Psychiatry 2020; published online April 30. https://doi.org.jnnp-2020-323522.

57 Solomon T, Michael BD, Smith PE, et al. Management of suspected viral encephalitis in adults-Association of British Neurologists and British Infection Association National Guidelines. J Infect 2012; 64: 347-73.

58 Pilotto A, Odolini S, Stefano Masciocchi S, et al. Steroid-responsive encephalitis in Coronoavirus disease 2019. Ann Neurol 2020; published online May 17. https://doi.org.10.1002/ana.25783.

59 Duong L, Xu P, Liu A. Meningoencephalitis without respiratory failure in a young female patient with COVID-19 infection in downtown Los Angeles, early April 2020. Brain Behav Immun 2020; published online April 17. https://doi.org.10.1016/ j.bbi.2020.04.024.

60 Vollono C, Rollo E, Romozzi M, et al. Focal status epilepticus as unique clinical feature of COVID-19: a case report. Seizure 2020; 78: 109-12.

61 Bernard-Valnet R, Pizzarotti B, Anichini A, et al. Two patients with acute meningo-encephalitis concomitant to SARS-CoV-2 infection. Eur J Neurol 2020; published online May 7. https://doi.org.10.1111/ ene.14298.

62 Wölfel R, Corman VM, Guggemos W, et al. Virological assessment of hospitalized patients with COVID-2019. Nature 2020; 581: 465-69.

63 Lee Y-L, Liao C-H, Liu P-Y, et al. Dynamics of anti-SARS-Cov-2 IgM and IgG antibodies among COVID-19 patients. J Infect 2020; published online April 23. https://doi.org.10.1016/j.jinf.2020.04.019.

64 Jin Y, Wang M, Zuo Z, et al. Diagnostic value and dynamic variance of serum antibody in coronavirus disease 2019. Int J Infect Dis 2020 94: 49-52.

65 Liu Y, Yan L-M, Wan L, et al. Viral dynamics in mild and severe cases of COVID-19. Lancet Infect Dis 2020; 20: 656-57.

66 He X, Lau EHY, Wu P, et al. Temporal dynamics in viral shedding and transmissibility of COVID-19. Nat Med 2020; 26: 672-75.

67 Xiang F, Wang X, He X, et al. Antibody detection and dynamic characteristics in patients with COVID-19. Clin Infect Dis 2020; published online April 19. https://doi.org.10.1093/cid/ciaa461.

68 Abdelnour L, Eltahir Abdalla M, Babiker S. COVID 19 infection presenting as motor peripheral neuropathy. J Formos Med Assoc 2020; 119: 1119-20.

69 Galán AV, del Saz Saucedo P, Postigo FP, Paniagua EB. Guillain-Barré syndrome associated with SARS-CoV-2 infection. Neurologia 2020; 35: 268-69. 
70 Marta-Enguita J, Rubio-Baines I, Gastón-Zubimendi I. Fatal Guillain-Barre syndrome after infection with SARS-CoV-2. Neurologia 2020; 35: 265-67.

71 Alberti P, Beretta S, Piatti M, et al. Guillain-Barré syndrome related to COVID-19 infection. Neurol Neuroimmunol Neuroinflamm 2020; 7: e741.

72 Virani A, Rabold E, Hanson T, et al. Guillain-Barré Syndrome associated with SARS-CoV-2 infection. IDCases 2020; 20: e00771.

73 Padroni M, Mastrangelo V, Asioli GM, et al. Guillain-Barré syndrome following COVID-19: new infection, old complication? J Neurol 2020; published online April 24. https://doi.org.10.1007/ s00415-020-09849-6.

74 El Otmani H, El Moutawakil B, Rafai M-A et al. Covid-19 and Guillain-Barré syndrome: more than a coincidence! Rev Neurol (Paris) 2020; 176: 518-19.

75 Coen M, Jeanson G, Culebras Almeida LA, et al. Guillain-Barré syndrome as a complication of SARS-CoV-2 infection. Brain Behav Immun 2020; published online April 28. https://doi.org.10.1016/j.bbi.2020.04.074.

76 Sharifi-Razavi A, Karimi N, Rouhani N. COVID-19 and intracerebral haemorrhage: causative or coincidental? New Microbes New Infect 2020; 35: 100669 .

77 Zhang Y, Xiao M, Zhang S, et al. Coagulopathy and antiphospholipid antibodies in patients with Covid-19. $N$ Engl J Med 2020; 382: e38.

78 Zhai P, Ding Y, Li Y. The impact of COVID-19 on ischemic stroke: a case report. Research Square 2020; published online March 31. https://doi.org/10.21203/rs.3.rs-20393/v1 (preprint).

79 Moshayedi P, Ryan TE, Mejia LLP, Nour M, Liebeskind DS. Triage of acute ischemic stroke in confirmed COVID-19: large vessel occlusion associated with coronavirus infection. Front Neurol 2020; 11: 353.

80 Slooter AJ, Otte WM, Devlin JW, et al. Updated nomenclature of delirium and acute encephalopathy: statement of ten Societies. Intensive Care Med 2020; 46: 1020-22.

81 Chacón-Aguilar R, Osorio-Cámara JM, Sanjurjo-Jimenez I, González-González C, López-Carnero J, Pérez-Moneo-Agapito B. COVID-19: fever syndrome and neurological symptoms in a neonate. An Pediatr 2020; published online April 27. https://doi.org.10.1016/j.anpede.2020.04.001.

82 Garazzino S, Montagnani C, Donà D, et al. Multicentre Italian study of SARS-CoV-2 infection in children and adolescents, preliminary data as at 10 April 2020. Euro Surveill 2020; 25: 2000600.

83 Pohl D, Alper G, Van Haren K, et al. Acute disseminated encephalomyelitis. Neurology 2016; 87 (9 suppl 2): S38-45.

84 Willison HJ, Jacobs BC, van Doorn PA. Guillain-Barré syndrome. Lancet 2016; 388: 717-27.

85 Jin M, Tong Q. Rhabdomyolysis as potential late complication associated with COVID-19. Emerg Infect Dis 2020; published online March 20. https://doi.org.10.3201/eid2607.200445.

86 Suwanwongse K, Shabarek N. Rhabdomyolysis as a presentation of 2019 novel coronavirus disease. Cureus 2020; 12: e7561.

87 Luers JC, Klussmann JP, Guntinas-Lichius O. The Covid-19 pandemic and otolaryngology: what it comes down to? Laryngorhinootologie 2020; 99: 287-91.

88 Bénézit F, Le Turnier P, Declerck C, et al. Utility of hyposmia and hypogeusia for the diagnosis of COVID-19. Lancet Infect Dis 2020; published online April 15. https://dx.doi.org/10.1016/ S1473-3099(20)30297-8.

89 Beltrán-Corbellini Á, Chico-García JL, Martínez-Poles J, et al. Acute-onset smell and taste disorders in the context of COVID-19: a pilot multicentre polymerase chain reaction based case-control study. Eur J Neurol 2020; published online April 22. https://doi. org.10.1111/ene.14273.

90 Moein ST, Hashemian SMR, Mansourafshar B, Khorram-Tousi A, Tabarsi P, Doty RL. Smell dysfunction: a biomarker for COVID-19. Int Forum Allergy Rhinol 2020; published online April 17. https://doi.org.10.1002/alr.22587.

91 Hornuss D, Lange B, Schröter N, Rieg S, Kern WV, Wagner D. Anosmia in COVID-19 patients. Clin Microbiol Infect 2020; published online May 25. https://doi.org.10.1016/j.cmi.2020.05.017.
92 Lodigiani C, Iapichino G, Carenzo L, et al. Venous and arterial thromboembolic complications in COVID-19 patients admitted to an academic hospital in Milan, Italy. Thromb Res 2020; 19: 9-14.

93 Benussi A, Pilotto A, Premi E, et al. Clinical characteristics and outcomes of inpatients with neurologic disease and COVID-19 in Brescia, Lombardy, Italy. Neurology 2020; published online May 22. https://doi.org.10.1212/WNL.0000000000009848.

94 Klok FA, Kruip MJHA, van der Meer NJM, et al. Incidence of thrombotic complications in critically ill ICU patients with COVID-19. Thromb Res 2020; 191: 145-47.

95 González-Pinto T, Luna-Rodríguez A, Moreno-Estébanez A Agirre-Beitia G, Rodríguez-Antigüedad A, Ruiz-Lopez M. Emergency room neurology in times of COVID-19: malignant ischaemic stroke and SARS-CoV-2 infection. Eur J Neurol 2020; published online April 30. https://doi.org.10.1111/ene.14286.

96 Lushina N, Kuo JS, Shaikh HA. Pulmonary, cerebral, and renal thromboembolic disease associated with COVID-19 infection. Radiology 2020; published online April 23. https://doi.org.10.1148/ radiol.2020201623.

97 Thachil J, Tang N, Gando S, et al. ISTH interim guidance on recognition and management of coagulopathy in COVID-19. J Thromb Haemost 2020; 18: 1023-26.

98 Solomon T. Encephalitis, and infectious encephalopathies In: Donaghy M, ed. Brain's diseases of the nervous system, 12th edn. Oxford: Oxford University Press, 2009.

99 Netland J, Meyerholz DK, Moore S, Cassell M, Perlman S. Severe acute respiratory syndrome coronavirus infection causes neuronal death in the absence of encephalitis in mice transgenic for human ACE2. J Virol 2008; 82: 7264-75.

100 Yan R, Zhang Y, Li Y, Xia L, Guo Y, Zhou Q. Structural basis for the recognition of SARS-CoV-2 by full-length human ACE2. Science 2020; 367: $1444-48$

101 Hamming I, Timens W, Bulthuis ML, Lely AT, Navis G van Goor H. Tissue distribution of ACE2 protein, the functional receptor for SARS coronavirus. A first step in understanding SARS pathogenesis. J Pathol 2004; 203: 631-37.

102 Chu H, Chan JF-W, Yuen TT-T, et al. Comparative tropism, replication kinetics, and cell damage profiling of SARS-CoV-2 and SARS-CoV with implications for clinical manifestations, transmissibility, and laboratory studies of COVID-19: an observational study. Lancet Microbe 2020; published April 21. https://dx.doi.org/10.1016/S2666-5247(20)30004-5.

103 Solomon T, Willison $\mathrm{H}$. Infectious causes of acute flaccid paralysis. Curr Opin Infect Dis 2003; 16: 375-81.

104 Varga Z, Flammer AJ, Steiger P, et al. Endothelial cell infection and endotheliitis in COVID-19. Lancet 2020; 395: 1417-18.

105 Lopes da Silva R. Viral-associated thrombotic microangiopathies. Hematol Oncol Stem Cell Ther 2011; 4: 51-59.

106 Brisse E, Wouters CH, Andrei G, Matthys P. How viruses contribute to the pathogenesis of hemophagocytic lymphohistiocytosis. Front Immunol 2017; 8: 1102.

107 Mehta P, McAuley DF, Brown M, Sanchez E, Tattersall RS, Manson JJ. COVID-19: consider cytokine storm syndromes and immunosuppression. Lancet 2020; 395: 1033-34.

108 Emsley HC, Hopkins SJ. Acute ischaemic stroke and infection: recent and emerging concepts. Lancet Neurol 2008; 7: 341-53.

109 Gilden D, Cohrs RJ, Mahalingam R, Nagel MA. Varicella zoster virus vasculopathies: diverse clinical manifestations, laboratory features, pathogenesis, and treatment. Lancet Neurol 2009; 8: 731-40.

110 Venkatesan A, Tunkel AR, Bloch KC, et al. Case definitions, diagnostic algorithms, and priorities in encephalitis: consensus statement of the international encephalitis consortium. Clin Infect Dis 2013; 57: 1114-28.

111 Bolton CF, Young GB, Zochodne DW. The neurological complications of sepsis. Ann Neurol 1993; 33: 94-100.

112 Turtle L. Respiratory failure alone does not suggest central nervous system invasion by SARS-CoV-2. J Med Virol 2020; 92: 705-06.

(C) 2020 Elsevier Ltd. All rights reserved. 